\title{
Aflibercept: a review of its use in the treatment of choroidal neovascularization due to age-related macular degeneration
}

This article was published in the following Dove Press journal:

Clinical Ophthalmology

17 December 2015

Number of times this article has been viewed

\author{
Chandrakumar \\ Balaratnasingam ${ }^{1-3}$ \\ Elona Dhrami-Gavazi ${ }^{1,2,4}$ \\ Jesse T McCann 1,2,4,5 \\ Quraish Ghadiali',2 \\ K Bailey Freund 1,2,4,5 \\ 'Vitreous-Retina-Macula Consultants \\ of New York, NY, USA; ${ }^{2}$ LuEsther \\ T Mertz Retinal Research Center, \\ Manhattan Eye, Ear and Throat \\ Hospital, New York, NY, USA; \\ ${ }^{3}$ Centre for Ophthalmology and \\ Visual Sciences, Lions Eye Institute, \\ University of Western Australia, \\ Perth, WA, Australia; ${ }^{4}$ Department of \\ Ophthalmology, Edward S Harkness \\ Eye Institute, Columbia University \\ College of Physicians and Surgeons, \\ New York, NY, USA; ${ }^{5}$ Department of \\ Ophthalmology, New York University \\ School of Medicine, New York, \\ NY, USA
}

Abstract: Choroidal neovascularization (CNV) due to age-related macular degeneration (AMD) is an important cause of visual morbidity globally. Modern treatment strategies for neovascular AMD achieve regression of CNV by suppressing the activity of key growth factors that mediate angiogenesis. Vascular endothelial growth factor (VEGF) has been the major target of neovascular AMD therapy for almost two decades, and there have been several intravitreally-administered agents that have enabled anatomical restitution and improvement in visual function with continual dosing. Aflibercept $\left(\right.$ EYLEA $\left.^{\mathbb{R}}\right)$, initially named VEGF Trapeye, is the most recent anti-VEGF agent to be granted US Food and Drug Administration approval for the treatment of neovascular AMD. Biologic advantages of aflibercept include its greater binding affinity for VEGF, a longer intravitreal half-life relative to other antiVEGF agents, and the capacity to antagonize growth factors other than VEGF. This paper provides an up-to-date summary of the molecular mechanisms mediating $\mathrm{CNV}$. The structural, pharmacodynamic, and pharmacokinetic advantages of aflibercept are also reviewed to rationalize the utility of this agent for treating CNV. Results of landmark clinical investigations, including VIEW 1 and 2 trials, and other important studies are then summarized and used to illustrate the efficacy of aflibercept for managing treatment-naïve $\mathrm{CNV}$, recalcitrant $\mathrm{CNV}$, and CNV due to polypoidal choroidal vasculopathy. Safety profile, patient tolerability, and quality of life measures related to aflibercept are also provided. The evidence provided in this paper suggests aflibercept to be a promising agent that can be used to reduce the treatment burden of neovascular AMD.

Keywords: age-related macular degeneration, aflibercept, choroidal neovascularization, vascular endothelial growth factor, clinical trial

\section{Introduction}

Age-related macular degeneration (AMD) is the leading cause of severe visual loss in people over the age of 65 years in the industrialized world. ${ }^{1}$ It is a bilateral, progressive disease that demonstrates great interindividual variability with respect to the rate of visual loss over time. ${ }^{2}$ The global burden of AMD is projected to increase over the next two decades, and thus, there is an urgent need to clarify the pathophysiology of this disease and to identify viable treatment strategies that will arrest disease-induced vision loss. ${ }^{3}$

Choroidal neovascularization $(\mathrm{CNV})$ is a complication that may occur during the natural course of AMD. ${ }^{4}$ In a study of individuals who were diagnosed with early or intermediate AMD at baseline visit, approximately $10 \%$ developed CNV over a median follow-up period of 6.3 years. ${ }^{5}$ Fortunately, significant progress has been
Correspondence: K Bailey Freund Vitreous Retina Macula Consultants of New York, 460 Park Avenue, 5th Floor, New York, NY 10022, USA

$\mathrm{Tel}+\mathrm{I} 21286 \mid 9797$

$\mathrm{Fax}+\mathrm{I} 2126280698$

Email kbfnyf@aol.com 
made in the management of neovascular AMD over the past two decades. Treatment paradigms have shifted from observation to laser photocoagulation, ${ }^{6}$ to photodynamic therapy, ${ }^{7}$ to submacular surgery, ${ }^{8}$ and, more recently, to the use of intravitreal vascular endothelial growth factor (VEGF) therapy. ${ }^{9}$ Regarding the latter therapeutic approach, in 2004 pegaptanib (Macugen ${ }^{\circledR}$; Eyetech Pharmaceuticals Inc, Palm Beach Gardens, FL, USA and Pfizer Inc, New York, NY, USA) was the first VEGF inhibitor to be approved by the US Food and Drug Administration (FDA) to demonstrate efficacy in clinical trials for treating neovascular AMD. ${ }^{10}$ However, the use of pegaptanib was quickly surpassed in most settings by newer agents that antagonized a broader range of VEGF isoforms. The MARINA ${ }^{11}$ and ANCHOR ${ }^{12}$ trials demonstrated the utility of ranibizumab (Lucentis; Genentech USA Inc, San Francisco, CA, USA) for managing neovascular $\mathrm{AMD}$, and this agent received approval by the FDA in 2006. Bevacizumab (Avastin, Genentech USA, Inc) has been used off label for many years for treating $\mathrm{CNV}$ and was shown to be noninferior to ranibizumab in the Comparison of AMD Treatment Trial (CATT) ${ }^{13}$ and Inhibition of VEGF in Age-related choroidal Neovascularization $(\text { IVAN })^{14}$ trial.

Aflibercept (EYLEA ${ }^{\circledR}$; Regeneron Pharmaceutical Inc, Tarrytown, NY, USA and Bayer Healthcare, Berlin, Germany), initially named VEGF Trap-eye, is the most recent antiVEGF agent to be granted FDA approval (2011) for treating neovascular AMD. The ocular formulation of aflibercept has been specifically purified and buffered to minimize the risk of eye toxicity when injected intravitreally. ${ }^{15}$ When administered in an intravenous formulation for oncologic indications, the drug is referred to as ziv-aflibercept (Zaltrap; Regeneron Pharmaceutical Inc). There is compelling evidence from laboratory and clinical research that aflibercept is efficacious for treating neovascular AMD. ${ }^{16}$ This paper is a systematic discussion of the pathophysiology of $\mathrm{CNV}$, the pharmacokinetic and pharmacodynamic advantages of aflibercept, and the efficacy of this agent for managing neovascular AMD.

\section{Cellular and molecular mechanisms of CNV}

Physiological concentrations of growth factors, cytokines, and metabolic substrates are required for normal cellular function in the outer retinal compartment. ${ }^{17}$ Retinal pigment epithelium (RPE) and glial cells are the predominant cell types to secrete growth factors in the human retina and are therefore critical determinants of retinal health and disease. ${ }^{18,19}$ Disturbances and imbalances in the concentrations of pro-/antiangiogenic factors can alter the metabolic environment of the outer retina and shift it from one that supports neuronal physiology to one that favors vascular proliferation in the context of neovascularization (NV). This shift can be due to insults that serve to deplete regional RPE and glial cell populations and thereby diminish the global availability of trophic substrates..$^{20}$ The shift may also be consequent to diseases that modulate the function of a normal population of cells through feedback mechanisms without altering cell structure and density. ${ }^{21}$ In most chorioretinal diseases, both mechanisms are likely to be involved.

Anatomical disturbances to the outer retina coupled with breakdown in the biological mechanisms that govern vascular function predispose to CNV. ${ }^{22,23}$ There has been great focus on the role of growth factor-mediated mechanisms in neovascular AMD with less attention paid to the contribution of structural outer retinal changes such as the loss of RPE integrity. ${ }^{24,25}$ The latter changes have been the focus of novel strategies that are being considered for the management of non-neovascular AMD. ${ }^{26}$ Specifically, the efficacy of antioxidant supplementation complement inhibitors including intravitreal anti-factor $\mathrm{D}$, ciliary neurotrophic factor, brimonidine tartrate, and visual cycle modulators is currently being investigated for the management of nonneovascular AMD. ${ }^{27}$

Angiogenic factors that are known to promote vascular proliferation in AMD include VEGF, ${ }^{28}$ platelet derived growth factor (PDGF), ${ }^{29}$ transforming growth factor- $\beta 1,{ }^{30}$ fibroblast growth factor (FGF) ${ }^{31}$ angiogenin, ${ }^{32}$ placental growth factor (PlGF), ${ }^{33}$ and basic FGFs. ${ }^{34}$ Known inhibitors of vascular proliferation include endostatin, ${ }^{35}$ thrombospondin, ${ }^{36}$ and pigment epithelium derived factor- $1 .{ }^{37}$ The putative roles of each of these factors in angiogenesis and $\mathrm{NV}$ are summarized in Table 1.

As neoplasms are highly vascularized, metabolically hyperactive tissues, there is significant overlap in the cellular pathways that govern tumor angiogenesis and CNV. Our understanding about the pathophysiology of neovascular AMD has been greatly aided by developments in oncology. ${ }^{38}$ Current knowledge about neovascular AMD pathogenesis can be summarized with the following sequence of structural and biochemical changes that occur in a stepwise fashion during the process of angiogenesis: ${ }^{39,40}$

1. Loss of endothelial cell tight junctions in the native vascular bed.

2. Increased vascular permeability and extravasation of proteins that over time form a biochemical scaffold and facilitate the migration of capillary buds. 
Table I Growth factors and enzymes involved in angiogenesis

\begin{tabular}{|c|c|}
\hline Growth factor/enzyme & Role in angiogenesis \\
\hline \multirow[t]{5}{*}{ Vascular endothelial growth factor ${ }^{28}$} & Mitosis and migration of endothelial cells \\
\hline & Formation of vessel lumina and fenestrations \\
\hline & Vasodilation \\
\hline & Chemotaxis of macrophages and monocytes \\
\hline & Increased matrix metalloproteinase activity \\
\hline \multirow[t]{3}{*}{ Platelet derived growth factor ${ }^{29}$} & Induces vasoconstriction and promotes angiogenesis \\
\hline & Stimulates synthesis and deposition of collagen by fibroblasts \\
\hline & Strong chemoattractant and mitogen for mesenchyme derived cells \\
\hline \multirow[t]{2}{*}{ Placental growth factor ${ }^{33}$} & Potentiates VEGF bioactivity \\
\hline & Migration and proliferation of endothelial cells \\
\hline \multirow[t]{3}{*}{ Fibroblast growth factor ${ }^{31}$} & Mitosis and migration of endothelial cells \\
\hline & Organization of endothelia into tube-like structures \\
\hline & Induces VEGF expression in endothelia \\
\hline \multirow[t]{3}{*}{ Angiogenin ${ }^{32}$} & Upregulates metalloproteinases \\
\hline & Endothelial migration and organization into tubular structures \\
\hline & Catalytic properties comparable to RNAse \\
\hline \multirow[t]{2}{*}{ Basic fibroblast growth factor ${ }^{34}$} & Endothelial cell proliferation and migration \\
\hline & Upregulation of metalloproteinases \\
\hline \multirow[t]{2}{*}{ Transforming growth factor-beta $\mathrm{I}^{30}$} & Induces endothelial apoptosis following activation by VEGF \\
\hline & Stimulates angiogenesis \\
\hline \multirow[t]{2}{*}{ Endostatin $^{35}$} & Inhibits proliferation and organization of endothelial cells \\
\hline & Inhibits metalloproteinases \\
\hline \multirow[t]{2}{*}{ Thrombospondin- $2^{36}$} & Inhibits endothelial cell proliferation and migration \\
\hline & Induction of apoptosis \\
\hline
\end{tabular}

Note: Putative roles of each pro- and antiangiogenic molecule are provided. Abbreviations: VEGF, vascular endothelial growth factor; RNAse, Ribonuclease.

3. Secretion of proteases by endothelia that degrade the extracellular matrix and propagate new endothelial cell proliferation and migration.

4. Maturation and organization of the proliferative network with subsequent formation of capillary lumina and envelopment by pericytes.

5. Establishment of tight junctions and basement membranes in the neovascular bed.

It is important to consider that although the NV occurring in AMD is typically termed "choroidal" neovascularization, it can originate from either the choroidal (type 1 or $2 \mathrm{NV}$ ) or retinal (type 3 ) vascular circulations. ${ }^{41,42}$ A recent paper by Jung et $\mathrm{al}^{43}$ demonstrated that type $3 \mathrm{NV}$ is the second most common subtype of $\mathrm{NV}$ in newly diagnosed, white AMD patients. These findings have major implications for hypotheses regarding the pathogenesis of AMD and suggest that a focused investigation of the retinal circulation may provide novel insights into the biology of NV. These findings also exemplify the importance of understanding the relationship between the deep retinal capillary beds and $\mathrm{NV}$ in AMD. This relationship is easily forgotten when old AMD nomenclature, such as "choroidal neovascularization", is used to denote all subtypes of NV. Fortunately, the definitions proposed by Gass ${ }^{44}$ and Freund et $a 1,{ }^{45}$ which have greater relevance for prognosticating disease course and long-term visual potential are increasingly being used in the clinical setting to subclassify NV.

VEGF is upregulated in response to ischemia,${ }^{46}$ hypoxia, ${ }^{47}$ inflammation, ${ }^{48}$ and trauma. ${ }^{49}$ In AMD, the initiating factors that induce VEGF upregulation are unclear. However, there is good experimental evidence to demonstrate that complement components of drusen such as $\mathrm{C} 3 \mathrm{a}$ and $\mathrm{C} 5 \mathrm{a}$ are involved in this process..$^{50}$ The accumulation of oxidized lipids in Bruch's membrane is also thought to play an important role in upregulation of VEGF and NV..$^{51}$ In addition to accumulation of lipid, there is likely to be an ischemic component, due to atrophy of the choriocapillaris, driving VEGF upregulation in AMD. ${ }^{52}$

As VEGF isoforms mediate many of the steps involved in angiogenesis, nullifying the effects of VEGF has become a powerful way to arrest the process of NV in AMD. This can be done by antagonizing VEGF receptor function or by direct binding to VEGF isoforms to reduce their ability to 
interact with VEGF receptors. In order to understand why aflibercept is an efficacious therapeutic agent for the management of $\mathrm{NV}$, a detailed understanding of the biological function of VEGF isoforms and receptors is required. These topics will be covered in the subsequent sections.

\section{VEGF isoforms and VEGF receptors}

The VEGF-PDGF supergene family includes VEGF-A, VEGF-B, VEGF-C, VEGF-D, VEGF-E, and PlGF. ${ }^{53}$ Of these, VEGF-A is the best-characterized member of the VEGFPDGF family. Molecules in the VEGF-PDGF family are structurally different but share varying degrees of homology with VEGF-A. ${ }^{54}$ Furthermore, members of the VEGF-PDGF family are distinguished by their affinity for various VEGF receptors (Table 2). ${ }^{55}$ As VEGF-A is most closely implicated in the biology of $\mathrm{CNV}$, it will be the focus of this review.

The VEGF gene is located on chromosome 6 and is encoded by 8 exons and separated by 7 introns. ${ }^{56}$ Alternative splicing of the VEGF-A gene generates five dominant VEGF-A isoforms (VEGF-A ${ }_{121}, V$ VEF-A ${ }_{145}, V$ VEF-A ${ }_{165}$, VEGF-A ${ }_{189}$, and VEGF-A ${ }_{206}$ ) that are differentiated by amino acid number, molecular weight, and receptor binding domains. ${ }^{55,57,58}$ In addition to the five major isoforms, other VEGF variants are also generated by alternative splicing of the VEGF gene, but the role of these variants in the pathophysiology of AMD is unclear. The five major isoforms have differing solubility; VEGF-A $\mathrm{A}_{121}$ is highly diffusible while VEGF-A ${ }_{189}$ and VEGF-A ${ }_{201}$ are tissue bound with poor solubility. ${ }^{28} \mathrm{VEGF}_{-\mathrm{A}_{165}}$ is postulated to be the major isoform involved in NV in the human eye and has intermediate solubility compared to the other isoforms.

Table 2 VEGF molecules, isoforms and their receptor targets on the endothelial surface

\begin{tabular}{|c|c|}
\hline $\begin{array}{l}\text { VEGF family } \\
\text { member }\end{array}$ & Binding receptors \\
\hline \multicolumn{2}{|l|}{ VEGF-A } \\
\hline Isoform-206 & Heparan-sulfate proteoglycan \\
\hline Isoform- 189 & Heparan-sulfate proteoglycan \\
\hline Isoform-165a & $\begin{array}{l}\text { VEGFR-I, VEGFR-2, heparan-sulfate } \\
\text { proteoglycan, neuropilin I, neuropilin } 2\end{array}$ \\
\hline Isoform- 445 & VEGFR-2, heparan-sulfate proteoglycan \\
\hline Isoform- $\left.12\right|^{a}$ & VEGFR-I, VEGFR-2, neuropilin I, neuropilin 2 \\
\hline VEGF-B & VEGFR-I, neuropilin-I \\
\hline VEGF-C & VEGFR-2 and 3 \\
\hline VEGF-D & VEGFR-2 and 3 \\
\hline VEGF-E & VEGFR-2, neuropilin-I \\
\hline
\end{tabular}

Note: ${ }^{\text {NNote }}$ the distinctions in the receptors and coreceptors to which each member of the VEGF family binds.

Abbreviation: VEGF, vascular endothelial growth factor.
VEGF receptors populate the surface of endothelial cells. ${ }^{58}$ VEGF can bind to three related receptor tyrosine kinases: VEGFR-1, VEGFR-2, and VEGFR-3. VEGF-A binds to VEGFR-1 and VEGFR-2 but not VEGFR-3. The latter receptor binds only to VEGF-C and VEGF-D. ${ }^{59}$ The extracellular domain of VEGFR-1 and -2 contain seven immunoglobulinlike domains. These receptors also have a transmembrane domain and a consensus tyrosine kinase sequence that is interrupted by a kinase-insert domain. VEGF-A also interacts with coreceptors heparin sulfate proteoglycans, neuropilin-1, and neuropilin-2, which are also located on the surface of endothelial cells. ${ }^{55}$ Coreceptors modulate the activity of VEGFR-1 and VEGFR-2. ${ }^{60}$ For example, neuropilin-2 receptor presents $\mathrm{VEGF}_{165}$ to VEGFR-2 in a manner that enhances the effectiveness of VEGFR-2 signal transduction. VEGF coreceptors do not exert any activity on cell function if they do not interact with VEGFR-1 or $-2 .{ }^{61}$

The process of VEGF receptor signaling is initiated by the binding of covalently linked VEGF dimers to the extracellular receptor domain. ${ }^{55}$ This results in the dimerization of two receptor monomers with resultant phosphorylation of tyrosine kinases in both the intracellular juxtamembrane domain, the tail of the receptor, and the kinase insert domain. The net effect of these biochemical changes is the recruitment of signaling molecules that activate various cellular pathways involved in angiogenesis. ${ }^{62}$

There are marked differences in the biological effects of VEGFR-1 and VEGFR-2 activation, and the functions of these two receptors are dichotomously opposed in many ways. ${ }^{58,62}$ There is good evidence to suggest that VEGFR-2 mediates most of the cellular responses underlying VEGFdriven angiogenesis including mitogenesis, vascular hyperpermeability, and microvascular remodeling. The function of VEGFR-1 is less well understood. However, it is known to behave as a decoy receptor that sequesters VEGF from VEGFR-2. ${ }^{58}$ By doing so, VEGFR-1 has the capacity to modulate the function of VEGFR-2. The differential function of VEGFR-1 and -2 is further supported by studies that have shown that these receptors are not equally upregulated following insults such as ischemia and hypoxia. ${ }^{63}$ Investigating the patterns of VEGFR-1 and -2 expression in various biological environments can therefore aid our understanding the role of VEGF isoforms in vascular homeostasis and proliferative vascular disease.

\section{Pharmacology of aflibercept}

Aflibercept is a fully humanized recombinant protein that is constructed from portions of the human VEGFR. ${ }^{64}$ It functions as a soluble decoy receptor that is $115 \mathrm{kDa}$ in size and is made 


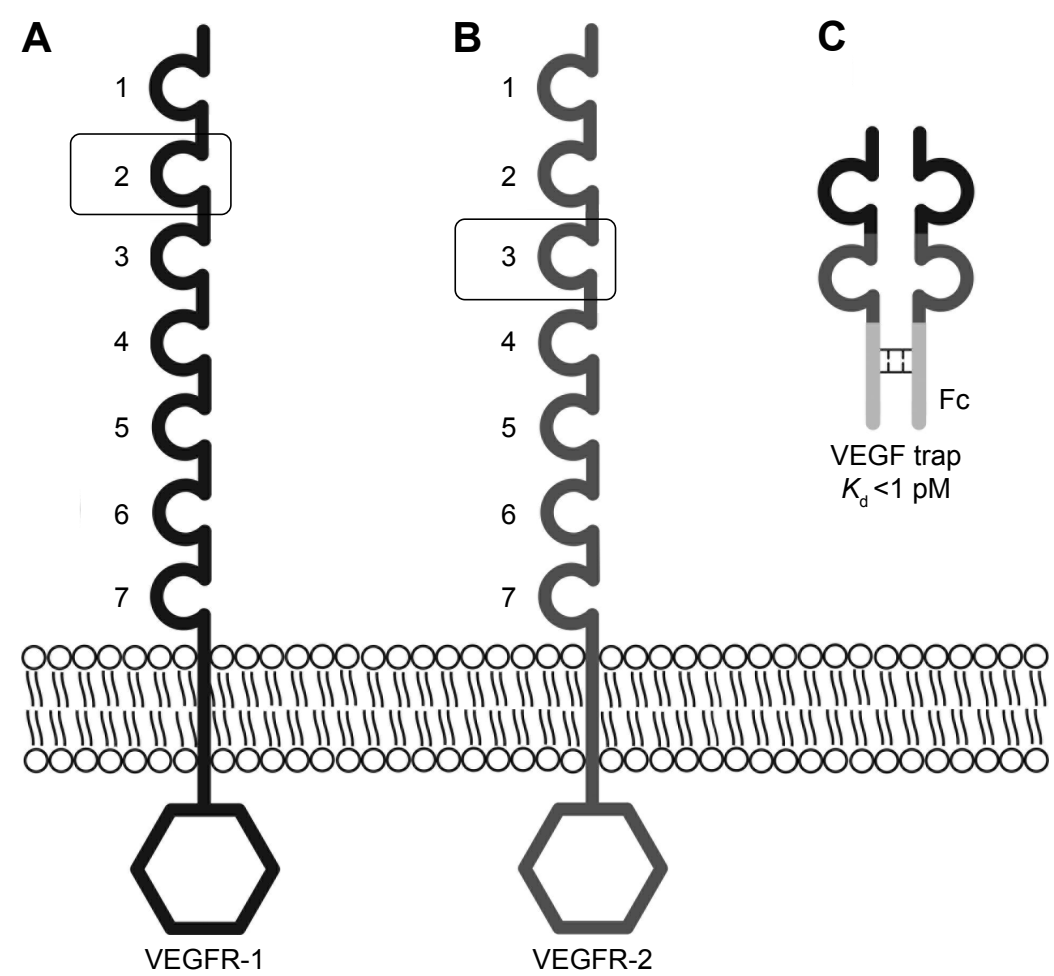

Figure I VEGF receptors and the structure of aflibercept.

Notes: VEGF receptor-I (A) and VEGF receptor-2 (B) are related receptors that have seven extracellular lg domains and an intracellular tyrosine kinase domain. VEGF trap (C) contains the Ig domain 2 of VEGF receptor-I fused to the Ig domain 3 of VEGF receptor-2, which is in turn fused to the IgGI Fc. Image obtained from VEGF Trap-Eye (aflibercept ophthalmic solution) Briefing Document. ${ }^{|3|}$

Abbreviation: VEGF, vascular endothelial growth factor; Ig, immunoglobulin; IgGI, immunoglobulin GI; Fc, fragment crystallizable.

by fusing the Fc region of human IgG1 to the second binding domain of VEGFR-1 and third binding domain of VEGFR-2 (Figure 1). ${ }^{65}$ The configuration of aflibercept facilitates binding to VEGF isoforms with greater affinity than the binding of VEGF to VEGFR-1 and VEGFR-2. The dissociation constant $\left[K_{\mathrm{d}}\right]$ of aflibercept for $\mathrm{VEGF}_{165}$ is $0.49 \mathrm{pmol} / \mathrm{L},{ }^{66}$ and the $K_{\mathrm{d}}$ of $\mathrm{VEGF}_{165}$ for VEGFR-1 and VEGFR-2 are 9.33 and 88.8 pmol/L, respectively. ${ }^{67}$ In addition to blocking VEGF-A isoforms, aflibercept has binding affinities to VEGF-B $\left(K_{\mathrm{d}}\right.$ $=352 \mathrm{pmol} / \mathrm{L})$ and PlGF-2 $\left(K_{\mathrm{d}}=17.5 \mathrm{pmol} / \mathrm{L}\right){ }^{66}$

A comparison of the structural and biochemical properties of aflibercept, ranibizumab, bevacizumab, and pegaptanib are provided in Table 3. A major functional distinction between aflibercept and other anti-VEGF agents is that it blocks VEGF-B, PIGF1, and PIGF-2 in addition to VEGF-A isoforms. Aflibercept antagonizes a broader spectrum of growth factors, and the potency of aflibercept for blocking VEGF-mediated signaling by $\mathrm{VEGF}_{121}$ and $\mathrm{VEGF}_{165}$ is greater than ranibizumab and bevacizumab by several orders of magnitude ${ }^{66}$ The affinity of aflibercept for VEGF-A ${ }_{165}$ is 94 times greater than ranibizumab and approximately 120 times greater than bevacizumab. ${ }^{66}$

The intravitreal half-life of aflibercept (4.7 days) is greater than ranibizumab, bevacizumab, and pegaptanib. ${ }^{68-71}$
Mathematical modeling has estimated that the intravitreal VEGF binding capacity of aflibercept $(1.15 \mathrm{mg}) 79$ days after injection is equivalent to the binding capacity of ranibizumab 30 days after injection. ${ }^{68}$ However, it is important to remember that these values were derived from experimental studies involving nonprimate animals (mainly rabbits) and so the results could be different if the experiments were performed in the human eye. To our knowledge, the half-life of aflibercept in the human eye has not been determined.

Intravitreally administered drugs are cleared by two main mechanisms: ${ }^{72}$

1. Anterior elimination pathway via counterdirectional aqueous flow;

2. Posterior elimination pathway via vitreoretinochoroidal bulk flow due to hydrostatic and osmotic pressure gradients in the posterior segment.

In order to reach the site of NV, intravitreal agents need to penetrate the different layers of the retina to enter the subretinal, sub-RPE, and intraretinal compartments. Fortunately, tight junctions are not a major anatomical feature of most retinal layers, ${ }^{73}$ and the vast majority of molecules experience an unhindered passage through the retina to reach the desired area of pathology. The major determinants of drug penetration include molecular size, charge, and lipid solubility. 
Table 3 Structural, pharmacodynamic, and pharmacokinetic properties of different anti-VEGF agents used in the clinical management of neovascular AMD

\begin{tabular}{|c|c|c|c|c|}
\hline & Aflibercept & Ranibizumab & Bevacizumab & Pegaptanib \\
\hline FDA approved & Yes & Yes & No (off label use) & Yes \\
\hline Structure/composition & $\begin{array}{l}\text { Human recombinant } \\
\text { fusion protein }\end{array}$ & $\begin{array}{l}\text { Humanized monoclonal } \\
\text { antibody fragment }\end{array}$ & $\begin{array}{l}\text { Whole humanized } \\
\text { monoclonal antibody }\end{array}$ & Aptamer (synthetic oligonucleotide) \\
\hline Size & $115 \mathrm{kDa}$ & $48 \mathrm{kDa}$ & 148 kDa & $\begin{array}{l}\text { 28-base RNA oligonucleotide with } \\
\text { two branched } 20 \mathrm{kDa} \text { PEG moieties }\end{array}$ \\
\hline Growth factor specificity & $\begin{array}{l}\text { All isoforms of VEGF-A, } \\
\text { VEGF-B, and PIGF }\end{array}$ & All isoforms of VEGF-A & $\begin{array}{l}\text { All isoforms of } \\
\text { VEGF-A }\end{array}$ & VEGF-A ${ }_{165}$ \\
\hline Intravitreal dose for AMD (mg) & 2 & 0.5 & 1.25 & 0.3 \\
\hline Intravitreal half life ${ }^{\mathrm{a}}$ (days) & 4.7 & 2.9 & 4.3 & 3.9 \\
\hline
\end{tabular}

Note: antravitreal half-life estimates were derived from experimental animal studies and not human eyes.

Abbreviations: VEGF, vascular endothelial growth factor; AMD, age-related macular degeneration; FDA, US Food and Drug Administration; PEG, polyethylene glycol; PIGF, placental growth factor.

Large cationic molecules are most resistant to permeating the retina. ${ }^{74}$ Full thickness retinal penetration has been demonstrated following intravitreal injection of bevacizumab, the largest of the anti-VEGF molecules in the rabbit eye. ${ }^{75}$ Similar studies have not been performed with aflibercept, but given the evidence that this agent is highly efficacious for treating type $1 \mathrm{NV}$ (as discussed in the subsequent sections), it is likely that aflibercept achieves high levels of transretinal penetration in human eyes with AMD.

The systemic half-life of aflibercept is approximately 1.5 days and is greater than that of ranibizumab (6 hours) and less than that of bevacizumab (20 days). ${ }^{68}$ Maximum systemic concentrations of aflibercept are achieved approximately 2-3 days after intravitreal injection, and these maximal concentrations are estimated to be approximately 200-fold less than the concentration required for maximal VEGF binding. ${ }^{76,77}$ Therefore, it is unlikely that aflibercept will reduce systemic VEGF concentrations to a level that will disrupt key homeostatic mechanisms required for normal cardiovascular function. Additionally, aflibercept has not been detected in the systemic circulation 2 weeks after intravitreal administration. ${ }^{78}$

Data from oncology trials have shown that systemic clearance of aflibercept occurs by two major pathways. ${ }^{15}$ The first pathway involves renal clearance following binding of VEGF, and this occurs when serum concentrations of aflibercept are relatively low. The second pathway occurs during states of relatively greater aflibercept concentration and involves pinocytic-mediated mechanisms and elimination by proteolysis.

\section{Alfibercept for the management of neovascular AMD \\ Preclinical trials}

The unique structural, pharmacodynamic, and pharmacokinetic properties of aflibercept make it ideally suited for treating neovascular AMD. One of the earliest studies to demonstrate the clinical efficacy of aflibercept examined its application for the management of laser-induced CNV and subretinal NV in transgenic mice. ${ }^{79}$ This study showed that suppression of choroidal and subretinal neovascularization could be achieved by subconjunctival and intravitreal administration of this agent. Many years later, the efficacy of aflibercept for treating laser-induced $\mathrm{CNV}$ in nonhuman primates was demonstrated by Nork et al. ${ }^{80}$

\section{Clinical trials}

Results of the first randomized, multicenter, placebo-controlled Phase I trial to examine the efficacy of aflibercept for treating CNV due to AMD were reported by Nguyen et al ${ }^{81}$ for the CLEAR (Clinical Evaluation of Antiangiogenesis in the Retina) Study Group. This trial evaluated the effects of intravenous administration of aflibercept in eyes with neovascular AMD. In this study, comparisons between 19 patients treated with intravenous aflibercept and 6 patients who received placebo showed that those eyes that received treatment with either single or multiple administrations of aflibercept experienced an average reduction of $60 \%$ excess retinal thickness. The maximum tolerated intravenous dose of aflibercept in the study group was deemed to be $1.0 \mathrm{mg} / \mathrm{kg}$ with the major causes of dose-limiting toxicity being hypertension and proteinuria. The anatomical improvement in retinal thickness following intravenous administration of aflibercept provided the impetus to explore the utility of intravitreal delivery even though a significant change in visual acuity was not noted after intravenous administration.

A subsequent dose escalation study was performed by the same investigators to determine the safety, tolerability, maximum tolerated dose, and bioactivity of intravitreal aflibercept ${ }^{82} \mathrm{~A}$ total of 21 patients were enrolled in this study and received a single dose of either $0.05,0.15,0.5,1,2$, or $4 \mathrm{mg}$ of aflibercept. The primary end point was 6 weeks, 
although some patients were followed for 12 weeks. The main outcome measures were related to safety, and there were no identifiable cases of intraocular inflammation or serious adverse effects in any of the subjects reported. The side effects of hypertension and proteinuria were also not encountered in study patients who received intravitreal therapy. Ninetyfive percent of patients in the study demonstrated stable or improved visual acuity at 6 weeks (mean gain of 4.43 letters) after intravitreal aflibercept regardless of the dose that was administered. The greatest visual gains were identified in those who received a dose of $1.0 \mathrm{mg}$ or greater (mean increase of 13.5 letters when 2 and $4 \mathrm{mg}$ groups were combined).

After the safety profile of intravitreal aflibercept for treating CNV was established, a Phase II clinical trial was undertaken by the CLEAR-IT 2 investigators. ${ }^{83}$ One hundred fifty-nine patients with subfoveal $\mathrm{CNV}$ were randomized into one of five groups. The first two groups received 0.5 or $2 \mathrm{mg}$ of aflibercept every 4 weeks for a total of 12 weeks. The other three groups received a dose of $0.5,2$, or $4 \mathrm{mg}$ of aflibercept at day 1 and 12 weeks (a total of two injections during the study period). The primary endpoint was change from baseline in central retinal thickness and lesion thickness at week 12. Best corrected visual acuity (BCVA) and other numeric changes in visual acuity were secondary outcome measures. At the 12-week endpoint, the groups that received therapy every 4 weeks showed the greatest improvement in visual acuity and reduction in retinal thickness. Interestingly, BCVA at the 8-week visit was not significantly different between the group receiving $2 \mathrm{mg}$ aflibercept every 4 weeks and the group receiving $2 \mathrm{mg}$ of aflibercept every 12 weeks. This finding led the authors to suggest that a dose of $2 \mathrm{mg}$ every 8 weeks may be as effective as dosing every 4 weeks. Furthermore, results at week 52 of the CLEAR-IT 2 study showed that pro re nata (PRN) dosing maintained the significant anatomic and vision improvements established during the 12-week fixed dosing period. ${ }^{83,84}$

\section{VIEW I and VIEW 2 clinical trials}

The "VEGF Trap-Eye: Investigation of Efficacy and Safety in Wet AMD" studies (VIEW 1 and VIEW 2) were two Phase III double-masked, multinational, parallel-group, active-controlled clinical trials that evaluated the clinical efficacy of aflibercept in a prospective fashion. The VIEW studies were the largest controlled trials of anti-VEGF agents in neovascular AMD ever performed. ${ }^{78,85}$ Both trials were similarly designed. Patients in VIEW 1 were randomized at 154 centers in the United States and Canada $(n=1,217)$. Patients in VIEW 2 were randomized at 172 centers in Europe, Middle East, Asia-Pacific, Australia, and Latin America $(n=1,240)$. Only one eye from each patient was included in the study. The pertinent inclusion/exclusion criteria and major design features of the VIEW studies on enrollment are summarized in Table 4.

Table 4 Key features of the study criteria for VIEW I and 2 clinical trials

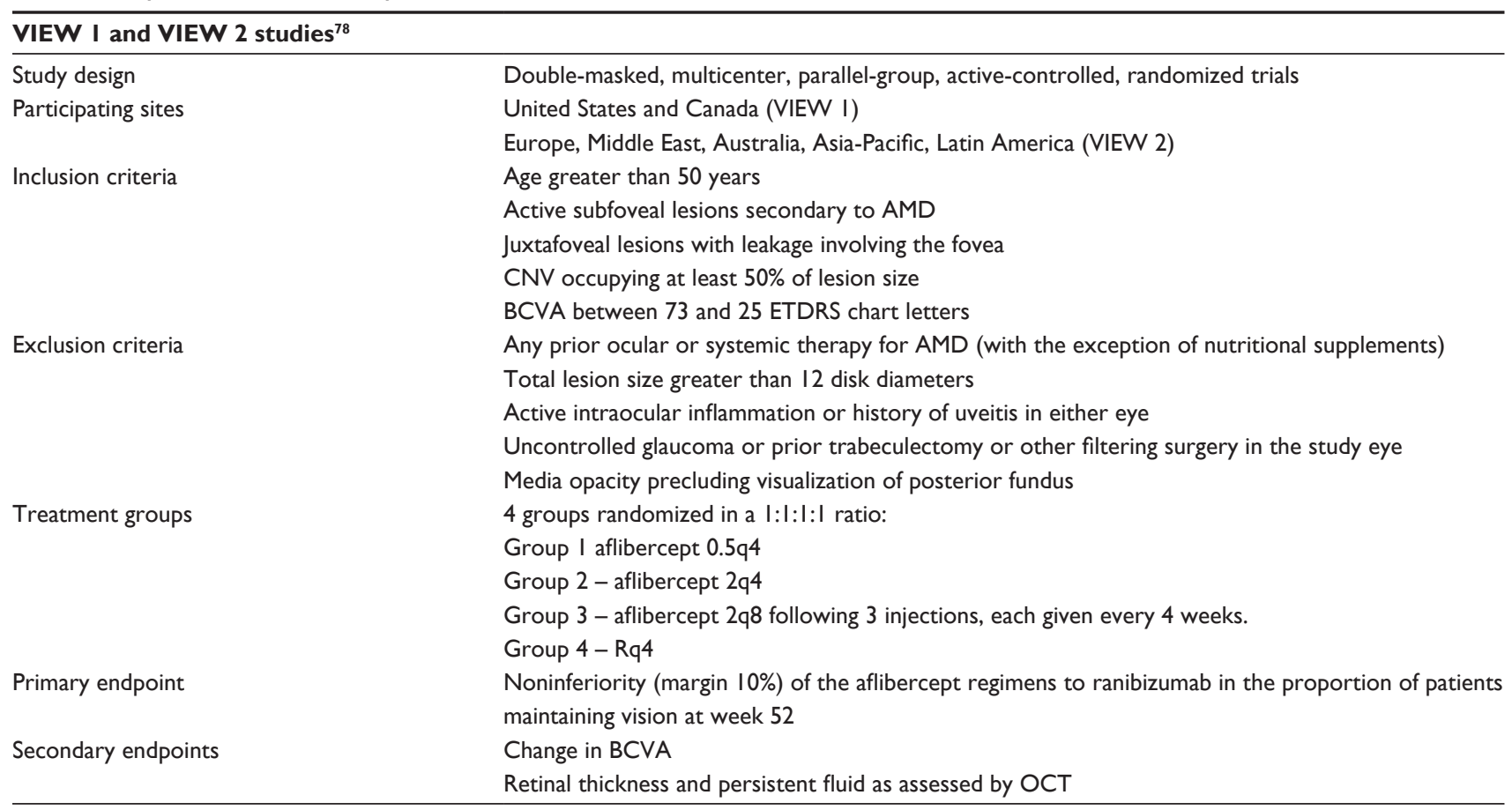

Abbreviations: VIEW, VEGF Trap-Eye: Investigation of Efficacy and Safety in Wet AMD; AMD, age-related macular degeneration; CNV, choroidal neovascularization; BCVA, best-corrected visual acuity; ETDRS, Early Treatment Diabetic Retinopathy Study; OCT, optical coherence tomography; $0.5 q 4,0.5$ mg IAI every 4 weeks; IAI, intravitreal aflibercept injection; 2q4, 2 mg IAl every 4 weeks; 2q8, 2 mg IAl every 8 weeks; Rq4, 0.5 mg ranibizumab every 4 weeks. 
Eligibility was determined by neovascular lesion characteristics based on fluorescein angiography.

There were 4 arms/treatment regimens evaluated in each of the VIEW studies. One regimen consisted of patients who were administered $0.5 \mathrm{mg}$ ranibizumab injections every 4 weeks (Rq4). Subjects in the other three treatment regimens received $0.5 \mathrm{mg}$ aflibercept every 4 weeks $(0.5 \mathrm{q} 4), 2 \mathrm{mg}$ aflibercept every 4 weeks ( $2 \mathrm{q} 4)$, or $2 \mathrm{mg}$ aflibercept every 8 weeks (2q8) following 3 injections, each given every 4 weeks. The primary endpoint of the VIEW 1 and 2 studies was non-inferiority of aflibercept regimens to ranibizumab in patients who maintained vision at 52 weeks. This was defined as losing less than 15 letters of visual acuity on the chart used in the Early Treatment Diabetic Retinopathy Study (ETDRS) ${ }^{78}$ Secondary measures included the change in BCVA, retinal thickness and fluid as judged using timedomain optical coherence tomography (OCT).

Integrated analysis of data from both VIEW studies at the 52-week visit showed non-inferiority of all three aflibercept treatment regimens compared to the ranibizumab regimen (Figure 2) ${ }^{78}$ All treatment regimens demonstrated a rapid increase in BCVA following the first injection, after which there were small and sustained increases in BCVA that persisted until week 52. Interestingly, the integrated data from both VIEW studies revealed that the mean visual acuity of all four treatment regimens was within 1 letter of each other at the 52-week visit. Mean change in BCVA from baseline to week 52 in the individual VIEW studies and in the integrated analysis is provided in Figure 3. Importantly, the mean visual acuity of the aflibercept group that was dosed every 8 weeks was within 0.3 letters of the ranibizumab group receiving dosing every 4 weeks. Regarding secondary outcome measures, all the aflibercept regimens were comparable to the monthly ranbizumab regimen in terms of reduction in retinal thickness and fluid.

From weeks 52 to 96 , the dosing schedule was changed to mandatory quarterly dosing with examination-guided interim injections that were also referred to as "capped-PRN dosing". Specifically, patients continued to be evaluated every 4 weeks. Mandatory treatment with the same dose of drug was administered every 12 weeks with treatment provided sooner if any one of the following criteria were identified during the 4-week review:

1. New or persistent fluid on OCT

2. Increase in central retinal thickness by $100 \mu \mathrm{m}$ or more on OCT

3. Loss of 5 or more letters on the ETDRS chart with recurrence of fluid on OCT

4. New onset classic CNV or new or persistent leakage on fluorescein angiography

5. New macular hemorrhage.

Ninety-one percent of the original cohort of subjects from VIEW 1 and 2 entered the second year of study. Eighty-four percent of the patients who enrolled in the study completed

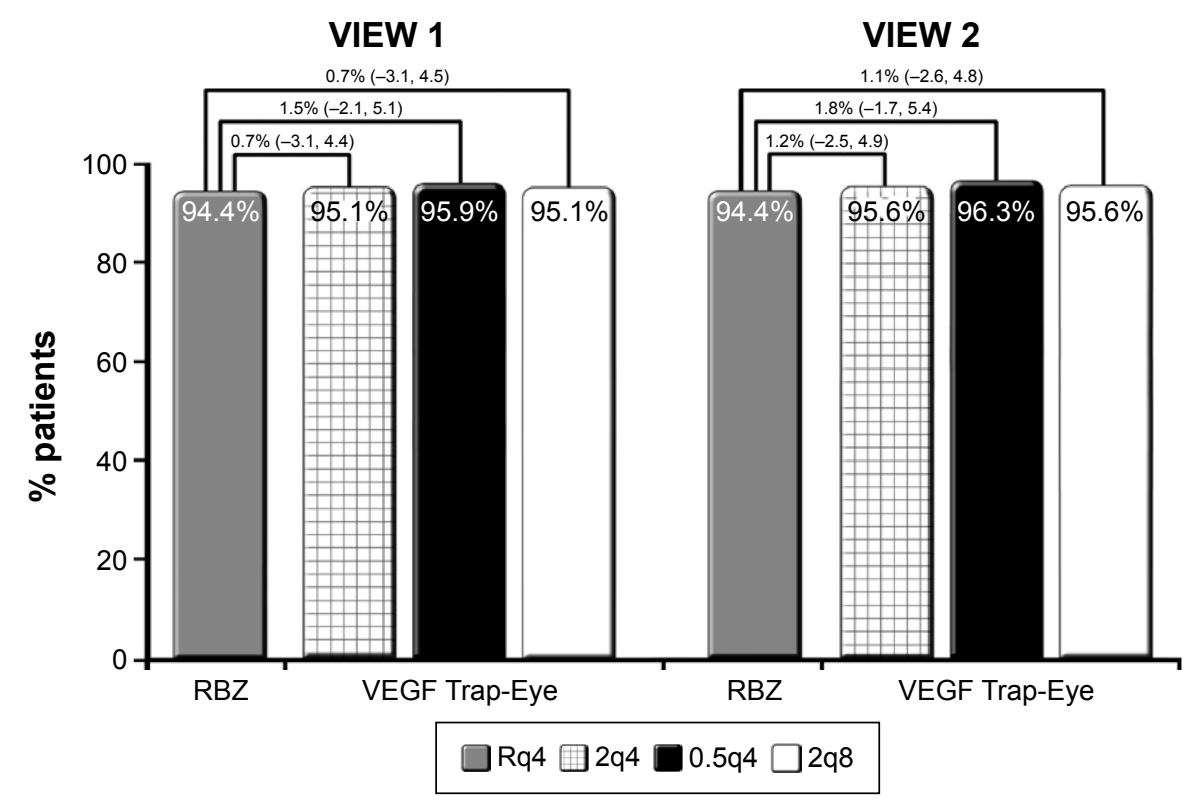

Figure 2 VIEW I and VIEW 2 primary endpoint: maintenance of vision at week 52.

Notes: Mean and confidence intervals for differences between groups are provided. Image obtained from VEGF Trap-Eye (aflibercept ophthalmic solution) Briefing Document. ${ }^{131}$ Abbreviations: VIEW, VEGF Trap-Eye: Investigation of Efficacy and Safety in Wet AMD; RBZ, ranibizumab; VEGF, vascular endothelial growth factor; Rq4, 0.5 mg ranibizumab every 4 weeks; 2q4, $2 \mathrm{mg} I \mathrm{AI}$ every 4 weeks; IAI, intravitreal aflibercept injection; 0.5q4, $0.5 \mathrm{mg} I \mathrm{AI}$ every 4 weeks; $2 q 8,2 \mathrm{mg} I \mathrm{AI}$ every 8 weeks after three initial 4-week doses. 

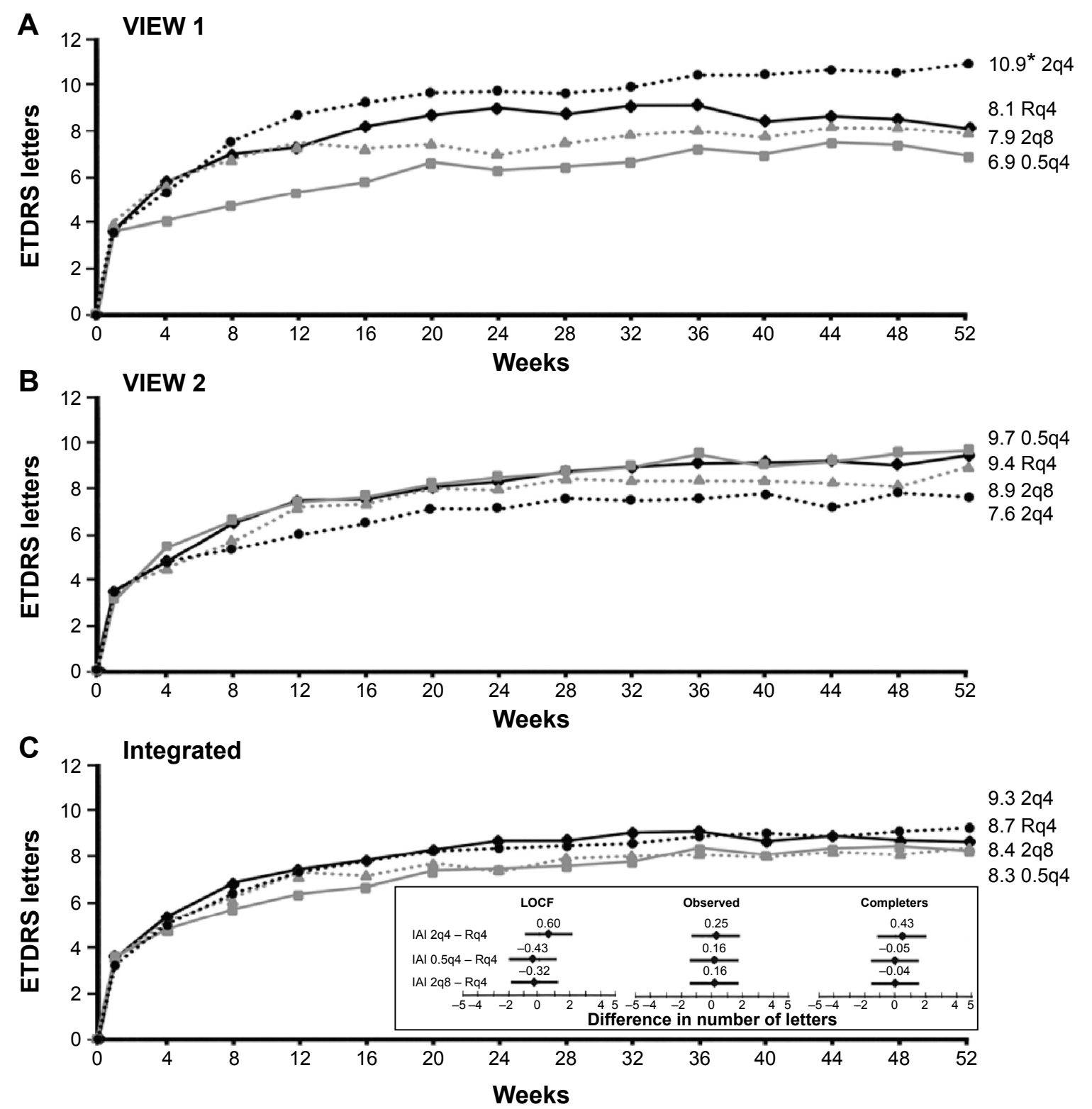

$\longrightarrow \mathrm{Rq} 4 \ldots . . .2 \mathrm{q} 4-0.5 \mathrm{q} 4 \ldots 2 \mathrm{C} 8$

Figure 3 Mean change in BCVA from baseline to week 52 in the (A) VIEW I study. (B) VIEW 2 study. (C) Integrated analysis.

Notes: Values in the line graphs refer to mean changes in the number of letters from baseline at week 52 . Only the intravitreal aflibercept $2 q 4$ arm in VIEW I was significantly different from ranibizumab ( ${ }^{*}=0.005$ for the difference). The panel inset (integrated analysis) shows the difference in visual acuity between each intravitreal aflibercept arm and ranibizumab (least-square mean with $95 \% \mathrm{Cl}$ ) at week 52, using three different analyses: by LOCF, using observed case data, and by assessing completers. Image obtained from VEGF Trap-Eye (aflibercept ophthalmic solution) Briefing Document. ${ }^{131}$

Abbreviations: VIEW, VEGF Trap-Eye: Investigation of Efficacy and Safety in Wet AMD; Rq4, 0.5 mg ranibizumab every 4 weeks; $0.5 q 4,0.5$ mg IAI every 4 weeks; IAI, intravitreal aflibercept injection; 2q4, 2 mg IAI every 4 weeks; 2q8, 2 mg IAI every 8 weeks after three initial 4-week doses; ETDRS, Early Treatment Diabetic Retinopathy Study; BCVA, best-corrected visual acuity; Cl, confidence interval; LOCF, last observation carried forward.

week 96. It was found that the mean increase in BCVA between baseline and the 96-week time point was comparable between the four treatment groups. At 96 weeks, the mean increase in BCVA across all four groups was approximately 7 letters on the ETDRS chart. The number of patients who gained 15 letters from baseline to 96 weeks was also similar across all groups. Post hoc comparisons of the number of injections administered between 52 and 96 weeks showed that the $2 \mathrm{q} 4$ ( $4.1 \pm 1.8$ injections) and $2 \mathrm{q} 8$ (4.2 \pm 1.7 injections) groups received significantly fewer injections than the Rq4 (4.7 \pm 2.2 injections) group. The lower number of injections administered in the capped-PRN phase of the VIEW studies may explain why there was a 1-2 letter loss in all groups between 52 and 96 weeks. It may also explain why the 
percentage of patients with no retinal fluid decreased from week 52 to 96 in all treatment groups.

The VIEW studies successfully highlighted the pharmacodynamic advantages of aflibercept in the clinical management of CNV due to AMD. The finding that patients in the $2 q 8$ group achieved visual and anatomic outcomes that were comparable to the $\mathrm{Rq} 4$ and $2 \mathrm{q} 4$ groups (with a mean of 5 fewer injections over 2 years) suggested that the use of aflibercept for the management of neovascular AMD could potentially be associated with fewer patient clinic visits. The other major finding to arise from VIEW studies was that switching from a fixed dosing to a capped-PRN protocol is likely to result in small losses of visual acuity as well as recurrence of anatomical changes such as fluid on OCT. The latter findings are similar to what was shown in the CATT trial. In the CATT trial, at the 2-year visit, the mean visual gain was significantly greater in patients treated with fixed dosing relative to the as-needed regimen. ${ }^{86}$

\section{Efficacy of aflibercept in nonresponders}

The characteristics of neovascular lesions with respect to cellular composition, expression of VEGF receptors, and, ultimately, response to antiangiogenic therapy are markedly heterogeneous. ${ }^{87}$ It is known that a distinct subset of neovascular lesions neither respond to anti-VEGF therapy in a predictable manner nor respond in a way that is consistent with the clinical course reported in large-scale trials. In the ophthalmic literature, these eyes are often denoted as "nonresponders" or eyes that have "failed therapy". 88

A number of studies have evaluated the rate of nonresponse to bevacizumab and ranibizumab therapy. The published estimates have varied from $10.1 \%$ to $45 \%{ }^{89-91}$ These estimates are, to a great extent, influenced by the definition of nonresponse, a nonstandardized term that varies significantly between different studies. Commonly used measures of nonresponse include decrease in BCVA, worsening of or new exudative findings, and the need for a greater frequency of injections to prevent progression of disease. Persistence or worsening of pigment epithelial detachment (PED), subretinal fluid, macular edema, hemorrhage, and increase/ no change in central retinal thickness are other measures of nonresponse. Increase in lesion size and leakage on dye angiography have also been described as failed therapy in some studies.

It is important to note that the terms refractory, treatmentresistant, and nonresponse are frequently used interchangeably in the ophthalmic literature. Recently, the expert panel review by Amoaku et $\mathrm{al}^{92}$ proposed a set of standardized nomenclature to define treatment response to anti-VEGF therapy in neovascular AMD. In that report, "nonresponse" was defined as those eyes that demonstrated a $>-5$ letter decline in Snellen visual acuity from baseline after the third injection in the initiation schedule of anti-VEGF therapy. It was also recommended that unchanging or increasing central retinal thickness, subretinal fluid, intraretinal fluid, and/or PED compared to the baseline visit should also be defined as nonresponse. ${ }^{92}$

One proposed reason for treatment nonresponse to anti-VEGF therapy is the time-dependent development of tachyphylaxis. Several biological mechanisms have been linked to the development of tachyphylaxis, ${ }^{93}$ and these include a compensatory upregulation of VEGF expression by macrophages at the site of $\mathrm{CNV}$ in response to repeated anti-VEGF therapy. Chronic changes to the vascular walls of CNV can also result in increased permeability to fluid and exudate and decreased response to anti-VEGF therapy. The development of neutralizing antibodies to therapeutic humanized monoclonal antibodies is also thought to contribute to the development of tachyphylaxis.

Clinical features that are thought to be predictive of nonresponse to anti-VEGF therapy include angiographic patterns that are consistent with occult $\mathrm{NV}$, type $1 \mathrm{NV}$, occurrence of a fibrovascular PED, relatively greater area of $\mathrm{NV}$ as determined using dye angiography, and poor reading ability at baseline visit. ${ }^{90}$ Age and number of injections were not significantly associated with treatment failure in the study by Ehlken et al. ${ }^{94}$ Treatment failure in that study was defined as no improvement or deterioration in visual acuity and retinal morphology, as seen on OCT, including an increase in intraretinal fluid and/or subretinal fluid.

The greater affinity of aflibercept for VEGF isoforms, its ability to antagonize the effects of PlGF and VEGF-B, and its longer intravitreal half-life are expected to confer unique biological advantages relative to other anti-VEGF agents. It is therefore plausible that aflibercept will have greater efficacy in the management of neovascular lesions when other anti-VEGF agents are deemed to have failed. Several studies have examined the role of aflibercept in the management of recurrent or refractory $\mathrm{NV}$, and these are summarized in Table 5. ${ }^{95-105}$ Most of these were retrospective studies that lacked a control group. There was also great variation between studies in the size of the treatment group and the treatment history prior to switching to aflibercept. Other variables that were not standardized between studies included the duration of follow-up and the indications for treatment switch. An exception is the prospective study by 


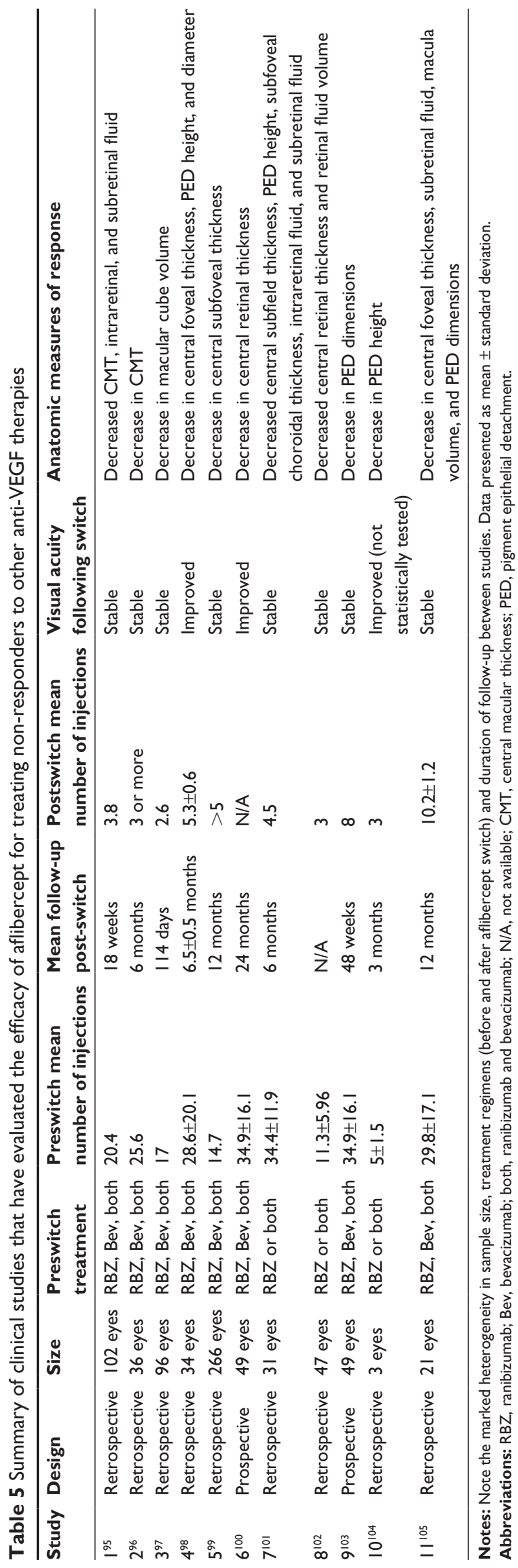

Chang et $\mathrm{al}^{100}$ that evaluated the effectiveness of intravitreal aflibercept in patients with treatment-resistant AMD. Treatment resistance in this study was defined as persistent intraretinal or subretinal fluid, as seen on spectral domainoptical coherence tomography, despite at least four injections of anti-VEGF agents in the past 6 months. BCVA was also required to be within the range of 35 and 90 ETDRS chart letters for inclusion in this trial. Forty-nine patients were recruited and followed for a 24-week period after switching to aflibercept. The investigators acknowledged that a limitation of this study was the lack of a control group.

All of the reviewed studies demonstrated significant anatomical improvement following the switch to aflibercept. OCT-based anatomical features that were shown to improve included a reduction in retinal thickness, macular volume, intraretinal fluid, subretinal fluid, or dimensions of the PED. With respect to BCVA, most studies demonstrated stabilization of visual acuity with the use of aflibercept, but only three studies ${ }^{98,100,104}$ demonstrated improvement in visual acuity. One of these three studies was a small case series that did not apply statistical techniques to validate the improvement in BCVA. ${ }^{104}$ The frequent dissociation between anatomic recovery and improvement in BCVA in nonresponders highlights the structure-function disconnect in AMD pathophysiology.

An editorial by Schachat ${ }^{106}$ discussed the limitations and advantages of many studies that have aimed at evaluating the efficacy of anti-VEGF treatment changes in presumed nonresponders. An important issue that was raised in this editorial is our current inability to predict the eyes that require a relatively longer course of treatment before a therapeutic response is seen. Specifically, Schachat ${ }^{106}$ suggested that it is possible for presumed nonresponders to improve over the course of time if the same drug was continued. Therefore, a switch may implicate an agent as being efficacious when really it was introduced at a point in a recalcitrant disease course at which improvement was looming. This is an important point that cannot be resolved with current clinical data. Large, randomized, prospective trials with control arms are therefore needed. Although there is broad clinical evidence to suggest that aflibercept has efficacy in the management of $\mathrm{NV}$ in nonresponders, these findings need to be validated using clinical trials with robust design and standardized inclusion/exclusion criteria.

\section{Aflibercept in PCV}

Polypoidal choroidal vasculopathy (PCV) has, for many years, been considered a variant of AMD. First described by Yannuzzi et al, ${ }^{107} \mathrm{PCV}$ was characterized by serosanguineous 
neovascular complications that were on the extreme scale of what was ordinarily encountered in AMD. Evaluation of eyes with PCV using indocyanine green angiography also identified polyps which were thought to be another clinical feature that distinguished PCV from AMD. ${ }^{108}$ The predilection for pigmented patients and those of Asian heritage also implicated a degree of inherited predisposition for PCV. ${ }^{109,110}$

Our understanding of the pathophysiology of PCV is currently limited. However, there is good evidence to suggest that the biological mechanisms driving angiogenesis and NV in PCV may be different from AMD. Eyes with PCV often do not manifest drusen, an important mediator of $\mathrm{NV}$ in AMD. There is also a greater likelihood for eyes with PCV to manifest a unique phenotypic choroidal manifestation, known as pachychoroid, which is structurally and functionally different from the normal human choroid. ${ }^{11-113}$ The recent shift to utilizing multimodal imaging to categorize degenerative chorioretinal diseases has refined our understanding of the pachychoroid phenotype. This definition of pachychoroid currently includes one or more of the following features:

1. Absolute increase in choroidal thickness.

2. Disproportional concentration of large, dilated pachyvessels at sites of pathology.

3. Diminution of the choriocapillaris layer in the setting of normal choroidal thickness.

Several studies have examined the efficacy of aflibercept for PCV. The study by Hosokawa et $\mathrm{al}^{114}$ showed that 6 months of intravitreal aflibercept achieved total resolution of polypoidal lesions in $77.7 \%$ of eyes and total resolution of retinal exudative changes in $94.4 \%$ of eyes. A significant decrease in central retinal thickness and improvements in BCVA were also achieved after 6 months of therapy. Similar results were also reported by Ijiri and Sugiyama ${ }^{115}$ after 3 months of aflibercept monotherapy. Recently, Yamamoto et $\mathrm{a}^{116}$ published the results of a larger retrospective study and provided the outcomes following 1 year of aflibercept therapy. One year of therapy resulted in similar improvements in BCVA and retinal thickness measurements as 3 and 6 months of treatment reported in other studies. However, this report demonstrated complete resolution of polypoidal lesions in only $55.4 \%$ of eyes. Furthermore, only $13.4 \%$ of eyes showed a decrease in the size of branching vascular networks after 1 year of treatment. Two different reports evaluated the efficacy of aflibercept in PCV subjects that did not respond to ranibizumab therapy. ${ }^{117,118}$ Both studies demonstrated significant improvements in BCVA and retinal thickness when treatment was switched to aflibercept.

As discussed, neovascular lesions in AMD and PCV may respond differently to anti-VEGF therapy because of important distinctions in the pathogenic mechanisms mediating the two diseases. The recent publication by Koizumi et $\mathrm{al}^{119}$ demonstrated that aflibercept therapy for PCV improved BCVA and induced a significant decrease in subfoveal choroidal thickness. Although their study was not designed to evaluate the relationship between BCVA and choroidal thickness, their findings, by extension, suggest that aflibercept may improve BCVA in PCV by addressing the spectrum of pachychoroid abnormalities. There is increasing evidence to suggest that PCV is best managed using a combination of photodynamic therapy (PDT) and intravitreal anti-VEGF. ${ }^{120}$ These findings further exemplify the biological differences between PCV and AMD; the latter infrequently requiring $\mathrm{PDT}$ for management.

\section{Safety and tolerability of aflibercept}

Intravitreal injection, of any therapeutic agent, is associated with risk of ocular adverse events that range from mild, self-limiting disease to serious complications that result in irrecoverable vision loss. The adverse events associated with intravitreal ranibizumab and bevacizumab have been provided in reports of large-scale clinical trials, ${ }^{13}$ and the most comprehensive documentation of adverse events related to intravitreal aflibercept use is provided in the VIEW studies. $^{78,85,121}$ Integrated results from over 2,000 subjects at the 96-week visit documented the frequency of several adverse events including conjunctival hemorrhage (range: 23.7\%-29.9\%), retinal hemorrhage (range: 13.6\%-16.2\%), reduced visual acuity (range: $11.3 \%-13.0 \%$ ), eye pain (range: $8.9 \%-12.1 \%$ ), vitreous detachment (range: $7.7 \%-10.0 \%$ ), and increased intraocular pressure (IOP; range: $6.2 \%-10.8 \%$ ). ${ }^{85}$ Only five cases of endophthalmitis were recorded from all aflibercept regimens from both VIEW studies. The same number was identified in the ranibizumab arm of both studies.

A number of reports have demonstrated an association between repeat intravitreal bevacizumab/ranibizumab injection and IOP elevation. ${ }^{122,123}$ Recently, Freund et al ${ }^{124}$ evaluated data from 2,457 patients from the VIEW studies to evaluate the relationship between IOP changes and intravitreal aflibercept use. Several metrics were used to study IOP changes including the following: 1) prevalence of IOP $>21 \mathrm{mmHg}$ through week 96 and 2) prevalence of IOP change from baseline of $\geq 10 \mathrm{mmHg}$ through week 96 . Their analysis revealed that at the week-96 visit the incidence of patients with an IOP change $\geq 10 \mathrm{mmHg}$ in the $2 \mathrm{q} 4,2 \mathrm{q} 8$, and $0.5 \mathrm{q} 4$ groups was $2.9 \%, 3.1 \%$, and $3.8 \%$, respectively. At the same visit, the incidence of patients with an IOP $>21 \mathrm{mmHg}$ in the $2 \mathrm{q} 4,2 \mathrm{q} 8$, and $0.5 q 4$ groups was $14.2 \%, 12.1 \%$, and $12.5 \%$, respectively. Interestingly, their analysis demonstrated that the incidence of elevated IOP in all aflibercept regimens was significantly 
lower than the ranibizumab regimen. The reason for the different degree of IOP changes observed in ranibizumab versus aflibercept treated eyes was unknown, but it was speculated that glycosylation of aflibercept may improve solubility in the vitreous cavity and reduce protein accumulation in the trabecular meshwork. Intravitreal aflbercept may therefore be preferable for managing neovascular AMD in patients with IOP concerns such as subjects with glaucoma, ocular hypertension, or a family history of glaucoma.

Systemic adverse effects following intravitreal antiVEGF therapy are uncommon. There has been some speculation about the association between anti-VEGF therapy and the occurrence of stroke, myocardial infarction, and bleeding. However, the retrospective cohort study of 146,942 Medicare beneficiaries did not demonstrate a significant risk of these complications or mortality between subjects receiving ranibizumab/bevacizumab and those receiving pegaptanib/ PDT. ${ }^{125}$ Data from the VIEW studies demonstrated that the incidence of Antiplatelet Trialists' Collaboration-defined arterial thromboembolic events was 3.3\% for pooled data from all aflibercept regimens at the 96-week visit and 3.2\% for the ranibizumab treatment arm. ${ }^{85}$ The incidence of these complications was not significantly different between treatment groups. The percentage of deaths in the Rq4, $2 \mathrm{q} 4$, $0.5 \mathrm{q} 4$, and $2 \mathrm{q} 8$ groups was $2.7 \%, 2.1 \%, 3.2 \%$, and $3.3 \%$, respectively. The incidence of death was also not different between treatment groups. Collectively, these results suggest that intravitreal administration has an acceptable safety profile and is well-tolerated by patients.

In recent times, there has been great concern about the increased risk of thromboembolic events in patients receiving intravitreal anti-VEGF therapy. There is now good evidence to show that the risk of these complications does not differ between the various anti-VEGF agents. ${ }^{126}$ There is also good evidence to show that the risk of arterial thromboembolic events in patients receiving long-term anti-VEGF therapy is not different to the elderly population not receiving antiVEGF therapy. Long-term results of PIER, IVAN, CATT, MARINA, ANCHOR, HORIZON, SECURE, and VIEW studies reported a rate of arterial thrombotic events between $3 \%$ and $5.6 \% .{ }^{126}$ In comparison, the crude incidence of myocardial infarction, an arterial thrombotic event, was determined to be 5.2 per 1,000 person-years following the evaluation of 26,185 subjects not receiving anti-VEGF therapy in the Tronso study. ${ }^{127}$

\section{Patient-focused perspectives}

Assessment of health-related quality of life outcome measures provides practical information about the effects of visual disability on a patient with eye disease. Such information is typically used to quantify the magnitude of visual loss as a result of disease. The 25-item National Eye Institute Visual Function Questionnaire (NEI VFQ-25) is a self-reported measure that has been utilized in anti-VEGF clinical trials to assess changes in vision-related function. ${ }^{128}$ It is a standardized, reliable, and reproducible measure of vision-related function that can be used to infer knowledge about a patient's capacity to satisfactorily complete activities of daily living.

Yuzawa et al ${ }^{129}$ recently published the analysis of NEI VFQ-25 questionnaires from VIEW studies up to and including the 52-week visit. Vision-related quality of life improvement was identified in six subscales including mental health, general vision, near activities, role difficulties, distance activities, and dependency. Wijeyakumar et al ${ }^{130}$ reported similar findings in a smaller cohort of subjects receiving aflibercept for neovascular AMD. In their study, they showed that patients with greater visual gain experienced a greater improvement in vision-related quality of life.

These findings have major implications as they demonstrate that aflibercept therapy improves an individual's capacity to function. An improvement in distance activities is likely to indicate decreased risk of falls due to improved mobility. An improvement in mental health may suggest a lower risk of depression. Yuzawa et al ${ }^{129}$ concluded that these benefits are likely to translate to less need for informal care giving, professional in-home help, and medical care transportation. It may also result in improved productivity in paid work or volunteer activities.

Analysis of VIEW trial data showed that there were minimal differences in subscale data between the group receiving aflibercept every 8 weeks and the group receiving ranibizumab every 4 weeks. In the VIEW trials, clinic visits were scheduled for assessment of visual acuity, OCT, and other clinical measures every 4 weeks for all groups even if therapy was not administered. By extension, this suggests that patients receiving aflibercept in routine clinical settings, where clinic visits could be scheduled every 8 weeks, would experience greater improvement in vision-related quality of life than what is provided from the VIEW trials.

\section{Conclusion}

There is strong evidence to demonstrate that intravitreal aflibercept is an efficacious therapeutic agent for managing treatment-naïve NV and recalcitrant NV due to AMD. Studies have shown that aflibercept is also effective in treating NV due to PCV. ${ }^{117,118}$ The unique pharmacodynamic and pharmacokinetic properties of aflibercept confer several biologic advantages in the management of $\mathrm{CNV}$. A major 
advantage of aflibercept, as demonstrated in several trials, is the requirement for less frequent dosing to achieve comparable visual and anatomical improvements as other agents. This is expected to translate to fewer clinic visits and potential cost-savings to the patient and the health-care system.

Integrated data from landmark clinical trials have shown that frequent intravitreal administration of aflibercept has an acceptable safety profile and is well-tolerated by patients. Visual gains as a result of aflibercept use are also associated with improvements in key measures of quality of life. For these reasons, aflibercept appears to be a suitable first-line therapy for neovascular AMD.

A number of new clinical trials including the Perseus-IT trial (A prospective Non-Interventional Study to Assess the Effectiveness of Aflibercept [Eyelea $\left.{ }^{\circledR}\right]$ ) in Routine Clinical Practice in Patients With Wet Age-related Macular Degeneration), the DRAW study (A Pharmacokinetic Study of Intravitreal Aflibercept in Vitrectomized and Non-vitrectomized Eyes with Wet Age-related Macular Degeneration), the RIVAL trial (A comparison of Ranibizumab and Aflibercept for the Development of Geographic Atrophy in [Wet] AMD Patients), and the SHIFT-2 trial (Intravitreal Aflibercept in Wet Age Related Macular Degeneration Patients With an Incomplete Response to Monthly Ranibizumab Injections) are designed to provide new, evidence-based information about the pharmacology and efficacy of aflibercept in various, atypical AMD settings. Results from these studies are expected to refine our knowledge about the role of aflibercept in AMD management.

\section{Acknowledgment}

LuEsther T. Mertz Retinal Research Center, Manhattan Eye, Ear and Throat Hospital/North Shore Long Island Jewish Hospital, New York, NY, USA, and The Macula Foundation, Inc., New York, NY, USA. The funding organizations had no role in the design or conduct of this research.

\section{Disclosure}

KB Freund is a consultant to Genentech, ThromboGenics, Ohr Pharmaceutical, Optos, Optovue, and Heidelberg Engineering (honorarium for each). The authors report no other conflicts of interest in this work.

\section{References}

1. Friedman DS, O'Colmain BJ, Munoz B, et al; Eye Diseases Prevalence Research Group. Prevalence of age-related macular degeneration in the United States. Arch Ophthalmol. 2004;122(4):564-572.

2. van Leeuwen R, Klaver CC, Vingerling JR, Hofman A, de Jong PT. The risk and natural course of age-related maculopathy: follow-up at $61 / 2$ years in the Rotterdam study. Arch Ophthalmol. 2003;121(4):519-526.
3. Wong WL, Su X, Li X, et al. Global prevalence of age-related macular degeneration and disease burden projection for 2020 and 2040: a systematic review and meta-analysis. Lancet Glob Health. 2014;2(2): e106-e116.

4. Barbazetto IA, Saroj N, Shapiro H, Wong P, Ho AC, Freund KB. Incidence of new choroidal neovascularization in fellow eyes of patients treated in the MARINA and ANCHOR trials. Am J Ophthalmol. 2010; 149(6):939-946.e931.

5. Clemons TE, Milton RC, Klein R, Seddon JM, Ferris FL 3rd; Age-Related Eye Disease Study Research Group. Risk factors for the incidence of Advanced Age-Related Macular Degeneration in the Age-Related Eye Disease Study (AREDS) AREDS report no. 19. Ophthalmology. 2005; 112(4):533-539.

6. Virgili G, Bini A. Laser photocoagulation for neovascular agerelated macular degeneration. Cochrane Database Syst Rev. 2007;(3): CD004763.

7. Treatment of age-related macular degeneration with photodynamic therapy (TAP) Study Group. Photodynamic therapy of subfoveal choroidal neovascularization in age-related macular degeneration with verteporfin: one-year results of 2 randomized clinical trials - TAP report. Arch Ophthalmol. 1999;117(10):1329-1345.

8. Eandi CM, Giansanti F, Virgili G. Macular translocation for neovascular age-related macular degeneration. Cochrane Database Syst Rev. 2008; (4):CD006928.

9. Solomon SD, Lindsley K, Vedula SS, Krzystolik MG, Hawkins BS. Antivascular endothelial growth factor for neovascular age-related macular degeneration. Cochrane Database Syst Rev. 2014;8:CD005139.

10. Singerman LJ, Masonson H, Patel M, et al. Pegaptanib sodium for neovascular age-related macular degeneration: third-year safety results of the VEGF Inhibition Study in Ocular Neovascularisation (VISION) trial. Br J Ophthalmol. 2008;92(12):1606-1611.

11. Rosenfeld PJ, Brown DM, Heier JS, et al. Ranibizumab for neovascular age-related macular degeneration. $N$ Engl J Med. 2006;355(14): 1419-1431.

12. Brown DM, Kaiser PK, Michels M, et al. Ranibizumab versus verteporfin for neovascular age-related macular degeneration. $N$ Engl J Med. 2006; 355(14):1432-1444.

13. Group CR, Martin DF, Maguire MG, et al. Ranibizumab and bevacizumab for neovascular age-related macular degeneration. $N$ Engl $J$ Med. 2011;364(20):1897-1908.

14. Chakravarthy U, Harding SP, Rogers CA, et al; IVAN Study Investigators. Alternative treatments to inhibit VEGF in age-related choroidal neovascularisation: 2-year findings of the IVAN randomised controlled trial. Lancet. 2013;382(9900):1258-1267.

15. Dixon JA, Oliver SC, Olson JL, Mandava N. VEGF trap-eye for the treatment of neovascular age-related macular degeneration. Expert Opin Investig Drugs. 2009;18(10):1573-1580.

16. Semeraro F, Morescalchi F, Duse S, Parmeggiani F, Gambicorti E, Costagliola C. Aflibercept in wet AMD: specific role and optimal use. Drug Des Devel Ther. 2013;7:711-722.

17. Bazan NG. Homeostatic regulation of photoreceptor cell integrity: significance of the potent mediator neuroprotectin D1 biosynthesized from docosahexaenoic acid: the Proctor Lecture. Invest Ophthalmol Vis Sci. 2007;48(11):4866-4881; biography 4864-4865.

18. Saint-Geniez M, Kurihara T, Sekiyama E, Maldonado AE, D'Amore PA. An essential role for RPE-derived soluble VEGF in the maintenance of the choriocapillaris. Proc Natl Acad Sci U S A. 2009;106(44): 18751-18756.

19. Bai Y, Ma JX, Guo J, et al. Muller cell-derived VEGF is a significant contributor to retinal neovascularization. J Pathol. 2009;219(4): 446-454.

20. Ablonczy Z, Dahrouj M, Marneros AG. Progressive dysfunction of the retinal pigment epithelium and retina due to increased VEGF-A levels. FASEB J. 2014;28(5):2369-2379.

21. Yang XM, Yafai Y, Wiedemann P, et al. Hypoxia-induced upregulation of pigment epithelium-derived factor by retinal glial (Muller) cells. J Neurosci Res. 2012;90(1):257-266. 
22. Shirinifard A, Glazier JA, Swat M, et al. Adhesion failures determine the pattern of choroidal neovascularization in the eye: a computer simulation study. PLoS Comput Biol. 2012;8(5):e1002440.

23. Campochiaro PA, Soloway P, Ryan SJ, Miller JW. The pathogenesis of choroidal neovascularization in patients with age-related macular degeneration. Mol Vis. 1999;5:34.

24. Funk M, Karl D, Georgopoulos M, et al. Neovascular age-related macular degeneration: intraocular cytokines and growth factors and the influence of therapy with ranibizumab. Ophthalmology. 2009;116(12): 2393-2399.

25. Muether PS, Neuhann I, Buhl C, Hermann MM, Kirchhof B, Fauser S. Intraocular growth factors and cytokines in patients with dry and neovascular age-related macular degeneration. Retina. 2013;33(9):1809-1814.

26. Girmens JF, Sahel JA, Marazova K. Dry age-related macular degeneration: a currently unmet clinical need. Intractable Rare Dis Res. 2012 1(3):103-114.

27. Singer M. Advances in the management of macular degeneration. F1000Prime Rep. 2014;6:29.

28. Grisanti S, Tatar $\mathrm{O}$. The role of vascular endothelial growth factor and other endogenous interplayers in age-related macular degeneration. Prog Retin Eye Res. 2008;27(4):372-390.

29. Jo N, Mailhos C, Ju M, et al. Inhibition of platelet-derived growth factor B signaling enhances the efficacy of anti-vascular endothelial growth factor therapy in multiple models of ocular neovascularization. Am J Pathol. 2006;168(6):2036-2053.

30. Ferrari G, Cook BD, Terushkin V, Pintucci G, Mignatti P. Transforming growth factor-beta 1 (TGF- $\beta 1)$ induces angiogenesis through vascular endothelial growth factor (VEGF)-mediated apoptosis. J Cell Physiol. 2009;219(2):449-458.

31. Ogata N, Matsushima M, Takada Y, et al. Expression of basic fibroblast growth factor mRNA in developing choroidal neovascularization. Curr Eye Res. 1996;15(10):1008-1018.

32. Skeie JM, Zeng S, Faidley EA, Mullins RF. Angiogenin in age-related macular degeneration. Mol Vis. 2011;17:576-582.

33. Rakic JM, Lambert V, Devy L, et al. Placental growth factor, a member of the VEGF family, contributes to the development of choroidal neovascularization. Invest Ophthalmol Vis Sci. 2003;44(7):3186-3193.

34. Frank RN, Amin RH, Eliott D, Puklin JE, Abrams GW. Basic fibroblast growth factor and vascular endothelial growth factor are present in epiretinal and choroidal neovascular membranes. Am J Ophthalmol. 1996; 122(3):393-403.

35. Tatar O, Shinoda K, Adam A, et al. Expression of endostatin in human choroidal neovascular membranes secondary to age-related macular degeneration. Exp Eye Res. 2006;83(2):329-338.

36. Wang S, Sorenson CM, Sheibani N. Lack of thrombospondin 1 and exacerbation of choroidal neovascularization. Arch Ophthalmol. 2012; 130(5):615-620.

37. Mori K, Duh E, Gehlbach P, et al. Pigment epithelium-derived factor inhibits retinal and choroidal neovascularization. J Cell Physiol. 2001 188(2):253-263.

38. Gunda V, Sudhakar YA. Regulation of tumor angiogenesis and choroidal neovascularization by endogenous angioinhibitors. J Cancer Sci Ther. 2013;5(12):417-426.

39. Das A, McGuire PG. Retinal and choroidal angiogenesis: pathophysiology and strategies for inhibition. Prog Retin Eye Res. 2003;22(6): 721-748.

40. Weis SM, Cheresh DA. Tumor angiogenesis: molecular pathways and therapeutic targets. Nat Med. 2011;17(11):1359-1370.

41. Yannuzzi LA, Negrao S, Iida T, et al. Retinal angiomatous proliferation in age-related macular degeneration. 2001. Retina. 2012;32(Suppl 1): 416-434.

42. Yannuzzi LA, Freund KB, Takahashi BS. Review of retinal angiomatous proliferation or type 3 neovascularization. Retina. 2008;28(3): 375-384.

43. Jung JJ, Chen CY, Mrejen S, et al. The incidence of neovascular subtypes in newly diagnosed neovascular age-related macular degeneration. Am J Ophthalmol. 2014;158(4):769-779.e762.
44. Gass JD. Stereoscopic Atlas of Macular Diseases. 4th ed. St Louis, MO: Mosby; 1997.

45. Freund KB, Zweifel SA, Engelbert M. Do we need a new classification for choroidal neovascularization in age-related macular degeneration? Retina. 2010;30(9):1333-1349.

46. Vinores SA, Youssri AI, Luna JD, et al. Upregulation of vascular endothelial growth factor in ischemic and non-ischemic human and experimental retinal disease. Histol Histopathol. 1997;12(1): 99-109.

47. Pe'er J, Folberg R, Itin A, Gnessin H, Hemo I, Keshet E. Vascular endothelial growth factor upregulation in human central retinal vein occlusion. Ophthalmology. 1998;105(3):412-416.

48. Weiss K, Steinbrugger I, Weger M, et al. Intravitreal VEGF levels in uveitis patients and treatment of uveitic macular oedema with intravitreal bevacizumab. Eye (Lond). 2009;23(9):1812-1818.

49. Skold MK, von Gertten C, Sandberg-Nordqvist AC, Mathiesen T, Holmin S. VEGF and VEGF receptor expression after experimental brain contusion in rat. J Neurotrauma. 2005;22(3):353-367.

50. Nozaki M, Raisler BJ, Sakurai E, et al. Drusen complement components C3a and C5a promote choroidal neovascularization. Proc Natl Acad Sci US A. 2006;103(7):2328-2333.

51. Spaide RF, Ho-Spaide WC, Browne RW, Armstrong D. Characterization of peroxidized lipids in Bruch's membrane. Retina. 1999; 19(2):141-147.

52. McLeod DS, Grebe R, Bhutto I, Merges C, Baba T, Lutty GA. Relationship between RPE and choriocapillaris in age-related macular degeneration. Invest Ophthalmol Vis Sci. 2009;50(10):4982-4991.

53. Holmes DI, Zachary I. The vascular endothelial growth factor (VEGF) family: angiogenic factors in health and disease. Genome Biol. 2005; 6(2):209.

54. Iyer S, Acharya KR. Tying the knot: the cystine signature and molecularrecognition processes of the vascular endothelial growth factor family of angiogenic cytokines. FEBS J. 2011;278(22):4304-4322.

55. Neufeld G, Cohen T, Gengrinovitch S, Poltorak Z. Vascular endothelial growth factor (VEGF) and its receptors. FASEB J. 1999;13(1):9-22.

56. Wei MH, Popescu NC, Lerman MI, Merrill MJ, Zimonjic DB. Localization of the human vascular endothelial growth factor gene, VEGF, at chromosome 6p12. Hum Genet. 1996;97(6):794-797.

57. Tischer E, Mitchell R, Hartman T, et al. The human gene for vascular endothelial growth factor. Multiple protein forms are encoded through alternative exon splicing. J Biol Chem. 1991;266(18):11947-11954.

58. Ferrara N, Gerber HP, LeCouter J. The biology of VEGF and its receptors. Nat Med. 2003;9(6):669-676.

59. Karkkainen MJ, Makinen T, Alitalo K. Lymphatic endothelium: a new frontier of metastasis research. Nat Cell Biol. 2002;4(1):E2-E5.

60. Olsson AK, Dimberg A, Kreuger J, Claesson-Welsh L. VEGF receptor signalling - in control of vascular function. Nat Rev Mol Cell Biol. 2006; 7(5):359-371.

61. Djordjevic S, Driscoll PC. Targeting VEGF signalling via the neuropilin co-receptor. Drug Discov Today. 2013;18(9-10):447-455.

62. Cebe-Suarez S, Zehnder-Fjallman A, Ballmer-Hofer K. The role of VEGF receptors in angiogenesis; complex partnerships. Cell Mol Life Sci. 2006;63(5):601-615.

63. Ulyatt C, Walker J, Ponnambalam S. Hypoxia differentially regulates VEGFR1 and VEGFR2 levels and alters intracellular signaling and cell migration in endothelial cells. Biochem Biophys Res Commun. 2011; 404(3):774-779

64. Aflibercept: AVE 0005, AVE 005, AVE0005, VEGF Trap-Regeneron, VEGF Trap (R1R2), VEGF Trap-Eye. Drugs $R$ D. 2008;9(4) 261-269.

65. Economides AN, Carpenter LR, Rudge JS, et al. Cytokine traps: multicomponent, high-affinity blockers of cytokine action. Nat Med. 2003; 9(1):47-52.

66. Papadopoulos N, Martin J, Ruan Q, et al. Binding and neutralization of vascular endothelial growth factor (VEGF) and related ligands by VEGF Trap, ranibizumab and bevacizumab. Angiogenesis. 2012; 15(2):171-185. 
67. Holash J, Davis S, Papadopoulos N, et al. VEGF-trap: a VEGF blocker with potent antitumor effects. Proc Natl Acad Sci US A. 2002; 99(17):11393-11398.

68. Stewart MW. What are the half-lives of ranibizumab and aflibercept (VEGF trap-eye) in human eyes? Calculations with a mathematical model. Eye Rep. 2011;1:e5.

69. Christoforidis JB, Carlton MM, Knopp MV, Hinkle GH. PET/CT imaging of I-124-radiolabeled bevacizumab and ranibizumab after intravitreal injection in a rabbit model. Invest Ophthalmol Vis Sci. 2011;52(8):5899-5903.

70. Bakri SJ, Snyder MR, Reid JM, Pulido JS, Ezzat MK, Singh RJ. Pharmacokinetics of intravitreal ranibizumab (Lucentis). Ophthalmology. 2007; 114(12):2179-2182.

71. Bakri SJ, Snyder MR, Reid JM, Pulido JS, Singh RJ. Pharmacokinetics of intravitreal bevacizumab (Avastin). Ophthalmology. 2007; 114(5):855-859.

72. Edelhauser HF, Rowe-Rendleman CL, Robinson MR, et al. Ophthalmic drug delivery systems for the treatment of retinal diseases: basic research to clinical applications. Invest Ophthalmol Vis Sci. 2010; 51(11):5403-5420.

73. Smelser GK, Ishikawa T, Pei YF. Electron Microscopic Studies of Intra-retinal Spaces: Diffusion of Particulate Materials. Vol II. Stuggart, Germany: Schattauer-Verlag; 1965.

74. Tornquist $\mathrm{P}$, Alm A, Bill A. Permeability of ocular vessels and transport across the blood-retinal-barrier. Eye (Lond). 1990;4(Pt 2):303-309.

75. Gaudreault J, Fei D, Beyer JC, et al. Pharmacokinetics and retinal distribution of ranibizumab, a humanized antibody fragment directed against VEGF-A, following intravitreal administration in rabbits. Retina. 2007;27(9):1260-1266.

76. Avery RL, Castellarin AA, Steinle NC, et al. Systemic pharmacokinetics following intravitreal injections of ranibizumab, bevacizumab or aflibercept in patients with neovascular AMD. Br J Ophthalmol. 2014; 98(12):1636-1641.

77. EYLEA ${ }^{\mathrm{TM}}$ (aflibercept) injection [US prescribing information]. Tarrytown, NY: Regeneron Pharmaceuticals, Inc; 2012.

78. Heier JS, Brown DM, Chong V, et al. Intravitreal aflibercept (VEGF trap-eye) in wet age-related macular degeneration. Ophthalmology. 2012;119(12):2537-2548.

79. Saishin Y, Saishin Y, Takahashi K, et al. VEGF-TRAP(R1R2) suppresses choroidal neovascularization and VEGF-induced breakdown of the blood-retinal barrier. J Cell Physiol. 2003;195(2):241-248.

80. Nork TM, Dubielzig RR, Christian BJ, et al. Prevention of experimental choroidal neovascularization and resolution of active lesions by VEGF trap in nonhuman primates. Arch Ophthalmol. 2011;129(8): 1042-1052.

81. Nguyen QD, Shah SM, Hafiz G, et al; CLEAR-AMD 1 Study Group. A phase I trial of an IV-administered vascular endothelial growth factor trap for treatment in patients with choroidal neovascularization due to age-related macular degeneration. Ophthalmology. 2006;113(9): 1522.e1-1522.e14.

82. Nguyen QD, Shah SM, Browning DJ, et al. A phase I study of intravitreal vascular endothelial growth factor trap-eye in patients with neovascular age-related macular degeneration. Ophthalmology. 2009;116(11):2141-2148.e2141.

83. Heier JS, Boyer D, Nguyen QD, et al; CLEAR-IT 2 Investigators. The 1-year results of CLEAR-IT 2, a phase 2 study of vascular endothelial growth factor trap-eye dosed as-needed after 12-week fixed dosing. Ophthalmology. 2011;118(6):1098-1106.

84. Brown DM, Heier JS, Ciulla T, et al; CLEAR-IT 2 Investigators. Primary endpoint results of a phase II study of vascular endothelial growth factor trap-eye in wet age-related macular degeneration. Ophthalmology. 2011;118(6):1089-1097.

85. Schmidt-Erfurth U, Kaiser PK, Korobelnik JF, et al. Intravitreal aflibercept injection for neovascular age-related macular degeneration: ninety-six-week results of the VIEW studies. Ophthalmology. 2014; 121(1):193-201.
86. Comparison of Age-related Macular Degeneration Treatments Trials Research Group; Martin DF, Maguire MG, Fine SL, et al. Ranibizumab and bevacizumab for treatment of neovascular age-related macular degeneration: two-year results. Ophthalmology. 2012;119(7): 1388-1398.

87. Park UC, Shin JY, McCarthy LC, et al. Pharmacogenetic associations with long-term response to anti-vascular endothelial growth factor treatment in neovascular AMD patients. Mol Vis. 2014;20:1680-1694.

88. Krebs I, Glittenberg C, Ansari-Shahrezaei S, Hagen S, Steiner I, Binder S. Non-responders to treatment with antagonists of vascular endothelial growth factor in age-related macular degeneration. $\mathrm{Br} J$ Ophthalmol. 2013;97(11):1443-1446.

89. Lux A, Llacer H, Heussen FM, Joussen AM. Non-responders to bevacizumab (Avastin) therapy of choroidal neovascular lesions. Br J Ophthalmol. 2007;91(10):1318-1322.

90. Suzuki M, Nagai N, Izumi-Nagai K, et al. Predictive factors for nonresponse to intravitreal ranibizumab treatment in age-related macular degeneration. Br J Ophthalmol. 2014;98(9):1186-1191.

91. Otsuji T, Nagai Y, Sho K, et al. Initial non-responders to ranibizumab in the treatment of age-related macular degeneration (AMD). Clin Ophthalmol. 2013;7:1487-1490.

92. Amoaku WM, Chakravarthy U, Gale R, et al. Defining response to anti-VEGF therapies in neovascular AMD. Eye (Lond). 2015; 29(10):1397-1398.

93. Forooghian F, Cukras C, Meyerle CB, Chew EY, Wong WT. Tachyphylaxis after intravitreal bevacizumab for exudative age-related macular degeneration. Retina. 2009;29(6):723-731.

94. Ehlken C, Jungmann S, Bohringer D, Agostini HT, Junker B, Pielen A. Switch of anti-VEGF agents is an option for nonresponders in the treatment of AMD. Eye (Lond). 2014;28(5):538-545.

95. Yonekawa Y, Andreoli C, Miller JB, et al. Conversion to aflibercept for chronic refractory or recurrent neovascular age-related macular degeneration. Am J Ophthalmol. 2013;156(1):29-35.e22.

96. Bakall B, Folk JC, Boldt HC, et al. Aflibercept therapy for exudative age-related macular degeneration resistant to bevacizumab and ranibizumab. Am J Ophthalmol. 2013;156(1):15-22.e11.

97. Ho VY, Yeh S, Olsen TW, et al. Short-term outcomes of aflibercept for neovascular age-related macular degeneration in eyes previously treated with other vascular endothelial growth factor inhibitors. Am J Ophthalmol. 2013;156(1):23-28.e22.

98. Kumar N, Marsiglia M, Mrejen S, et al. Visual and anatomical outcomes of intravitreal aflibercept in eyes with persistent subfoveal fluid despite previous treatments with ranibizumab in patients with neovascular age-related macular degeneration. Retina. 2013;33(8):1605-1612.

99. Cho H, Weber ML, Shah CP, Heier JS. Initial utilization of aflibercept in exudative age-related macular degeneration. Eur J Ophthalmol. 2014;24(4):576-581.

100. Chang AA, Li H, Broadhead GK, et al. Intravitreal aflibercept for treatment-resistant neovascular age-related macular degeneration. Ophthalmology. 2014;121(1):188-192.

101. Gharbiya M, Iannetti L, Parisi F, De Vico U, Mungo ML, Marenco M. Visual and anatomical outcomes of intravitreal aflibercept for treatment-resistant neovascular age-related macular degeneration. Biomed Res Int. 2014;2014:273754.

102. Griffin DR, Richmond PP, Olson JC. Intravitreal aflibercept outcomes in patients with persistent macular exudate previously treated with bevacizumab and/or ranibizumab for neovascular age-related macular degeneration. J Ophthalmol. 2014;2014:497178.

103. Broadhead GK, Hong T, Zhu M, et al. Response of pigment epithelial detachments to intravitreal aflibercept among patients with treatmentresistant neovascular age-related macular degeneration. Retina. 2015;35(5):975-981.

104. Patel KH, Chow CC, Rathod R, et al. Rapid response of retinal pigment epithelial detachments to intravitreal aflibercept in neovascular age-related macular degeneration refractory to bevacizumab and ranibizumab. Eye (Lond). 2013;27(5):663-667; quiz 668. 
105. Grewal DS, Gill MK, Sarezky D, Lyon AT, Mirza RG. Visual and anatomical outcomes following intravitreal aflibercept in eyes with recalcitrant neovascular age-related macular degeneration: 12-month results. Eye (Lond). 2014;28(7):895-899.

106. Schachat AP. Switching anti-vascular endothelial growth factor therapy for neovascular age-related macular degeneration. Am J Ophthalmol. 2013;156(1):1-2.e1.

107. Yannuzzi LA, Sorenson J, Spaide RF, Lipson B. Idiopathic polypoidal choroidal vasculopathy (IPCV). 1990. Retina. 2012;32(Suppl 1): $1-8$.

108. Spaide RF, Yannuzzi LA, Slakter JS, Sorenson J, Orlach DA. Indocyanine green videoangiography of idiopathic polypoidal choroidal vasculopathy. Retina. 1995;15(2):100-110.

109. Wen F, Chen C, Wu D, Li H. Polypoidal choroidal vasculopathy in elderly Chinese patients. Graefes Arch Clin Exp Ophthalmol. 2004; 242(8):625-629.

110. Ciardella AP, Donsoff IM, Huang SJ, Costa DL, Yannuzzi LA. Polypoidal choroidal vasculopathy. Surv Ophthalmol. 2004;49(1):25-37.

111. Dansingani K, Naysan J, Balaratnasingam C, Freund K. En Face imaging of pachychoroid spectrum disorders with swept-source optical coherence tomography. Retina. Epub August 12, 2015

112. Balaratnasingam C, Lee WK, Koizumi H, Dansingani KK, Inoue M, Freund KB. Polypoidal choroidal vasculopathy: a distinct disease or manifestation of many? Retina. Epub September 23, 2015

113. Gallego-Pinazo R, Dolz-Marco R, Gomez-Ulla F, Mrejen S, Freund KB. Pachychoroid diseases of the macula. Med Hypothesis Discov Innov Ophthalmol. 2014;3(4):111-115.

114. Hosokawa M, Shiraga F, Yamashita A, et al. Six-month results of intravitreal aflibercept injections for patients with polypoidal choroidal vasculopathy. Br J Ophthalmol. 2015;99(8):1087-1091.

115. Ijiri S, Sugiyama K. Short-term efficacy of intravitreal aflibercept for patients with treatment-naive polypoidal choroidal vasculopathy. Graefes Arch Clin Exp Ophthalmol. 2015;253(3):351-357.

116. Yamamoto A, Okada AA, Kano M, et al. One-year results of intravitreal aflibercept for polypoidal choroidal vasculopathy. Ophthalmology. Epub September 16, 2015.

117. Yamashita M, Nishi T, Hasegawa T, Ogata N. Response of serous retinal pigment epithelial detachments to intravitreal aflibercept in polypoidal choroidal vasculopathy refractory to ranibizumab. Clin Ophthalmol. 2014;8:343-346.

118. Miura M, Iwasaki T, Goto H. Intravitreal aflibercept for polypoidal choroidal vasculopathy after developing ranibizumab tachyphylaxis. Clin Ophthalmol. 2013;7:1591-1595.

119. Koizumi H, Kano M, Yamamoto A, et al. Short-term changes in choroidal thickness after aflibercept therapy for neovascular age-related macular degeneration. Am J Ophthalmol. 2015;159(4):627-633.

120. Ruamviboonsuk P, Tadarati M, Vanichvaranont S, Hanutsaha P, Pokawattana N. Photodynamic therapy combined with ranibizumab for polypoidal choroidal vasculopathy: results of a 1-year preliminary study. Br J Ophthalmol. 2010;94(8):1045-1051.
121. Ogura Y, Terasaki H, Gomi F, et al; VIEW 2 Investigators. Efficacy and safety of intravitreal aflibercept injection in wet age-related macular degeneration: outcomes in the Japanese subgroup of the VIEW 2 study. Br J Ophthalmol. 2015;99(1):92-97.

122. Hoang QV, Mendonca LS, Della Torre KE, Jung JJ, Tsuang AJ, Freund KB. Effect on intraocular pressure in patients receiving unilateral intravitreal anti-vascular endothelial growth factor injections. Ophthalmology. 2012;119(2):321-326.

123. Hoang QV, Tsuang AJ, Gelman R, et al. Clinical predictors of sustained intraocular pressure elevation due to intravitreal anti-vascular endothelial growth factor therapy. Retina. 2013;33(1):179-187.

124. Freund KB, Hoang QV, Saroj N, Thompson D. Intraocular pressure in patients with neovascular age-related macular degeneration receiving intravitreal aflibercept or ranibizumab. Ophthalmology. 2015;122(9):1802-1810.

125. Curtis LH, Hammill BG, Schulman KA, Cousins SW. Risks of mortality, myocardial infarction, bleeding, and stroke associated with therapies for age-related macular degeneration. Arch Ophthalmol. 2010;128(10):1273-1279.

126. Semeraro F, Morescalchi F, Duse S, Gambicorti E, Romano MR, Costagliola C. Systemic thromboembolic adverse events in patients treated with intravitreal anti-VEGF drugs for neovascular age-related macular degeneration: an overview. Expert Opin Drug Saf. 2014; 13(6):785-802.

127. Braekkan SK, Hald EM, Mathiesen EB, et al. Competing risk of atherosclerotic risk factors for arterial and venous thrombosis in a general population: the Tromso study. Arterioscler Thromb Vasc Biol. 2012;32(2):487-491.

128. Mangione CM, Lee PP, Gutierrez PR, Spritzer K, Berry S, Hays RD; National Eye Institute Visual Function Questionnaire Field Test I. Development of the 25-item National Eye Institute Visual Function Questionnaire. Arch Ophthalmol. 2001;119(7):1050-1058.

129. Yuzawa M, Fujita K, Wittrup-Jensen KU, et al. Improvement in vision-related function with intravitreal aflibercept: data from phase 3 studies in wet age-related macular degeneration. Ophthalmology. 2015;122(3):571-578.

130. Wijeyakumar W, Hong T, Broadhead T, Li H, Zhu M, Chang AA. Changes in quality of life among patients treated with aflibercept for neovascular age-related macular degeneration (nAMD). Poster presented at: ARVO 2014 Annual Meeting Abstracts, May 6, 2014, Orlando, FL.

131. VEGF Trap-Eye (aflibercept ophthalmic solution) Briefing Document. Available from: http:/www.fda.gov/downloads/AdvisoryCommittees/CommitteesMeetingMaterials/Drugs/DermatologicandOphthalmicDrugsAdvisoryCommittee/UCM259143.pdf. Accessed November 17,2015
Clinical Ophthalmology

\section{Publish your work in this journal}

Clinical Ophthalmology is an international, peer-reviewed journal covering all subspecialties within ophthalmology. Key topics include: Optometry; Visual science; Pharmacology and drug therapy in eye diseases; Basic Sciences; Primary and Secondary eye care; Patient Safety and Quality of Care Improvements. This journal is indexed on Submit your manuscript here: http://www.dovepress.com/clinical-ophthalmology-journal

\section{Dovepress}

PubMed Central and CAS, and is the official journal of The Society of Clinical Ophthalmology (SCO). The manuscript management system is completely online and includes a very quick and fair peer-review system, which is all easy to use. Visit http://www.dovepress.com/ testimonials.php to read real quotes from published authors. 